\title{
A Review on State-of-the-Art Power Converters: Bidirectional, Resonant, Multilevel Converters and Their Derivatives
}

\author{
Salah Alatai ${ }^{1}\left(\mathbb{D}\right.$, Mohamed Salem $^{1, * \mathbb{D}}$, Dahaman Ishak ${ }^{1} \mathbb{D}$, Himadry Shekhar Das ${ }^{2} \mathbb{D}_{\text {, }}$ \\ Mohammad Alhuyi Nazari ${ }^{3}$, Ali Bughneda ${ }^{1}$ (D) and Mohamad Kamarol ${ }^{1}$ (D)
}

1 School of Electrical and Electronic Engineering, Universiti Sains Malaysia (USM), Nibong Tebal, Seberang Perai 14300, Penang, Malaysia; salahalatai@student.usm.my (S.A.); dahaman@usm.my (D.I.); bughneda@student.usm.my (A.B.); eekamarol@usm.my (M.K.)

2 Department of Electrical and Computer Engineering, The University of Alabama, Tuscaloosa, AL 35401, USA; hdas@crimson.ua.edu

3 Faculty of New Sciences and Technologies, University of Tehran, Tehran 1417935840, Iran; nazari.mohammad.a@alumni.ut.ac.ir

* Correspondence: salemm@usm.my; Tel.: +60-1729-49514

check for

updates

Citation: Alatai, S.; Salem, M.; Ishak, D.; Das, H.S.; Alhuyi Nazari, M.; Bughneda, A.; Kamarol, M. A Review on State-of-the-Art Power Converters Bidirectional, Resonant, Multilevel Converters and Their Derivatives Appl. Sci. 2021, 11, 10172. https:// doi.org/10.3390/app112110172

Academic Editor: Eladio

Durán Aranda

Received: 30 September 2021

Accepted: 26 October 2021

Published: 29 October 2021

Publisher's Note: MDPI stays neutral with regard to jurisdictional claims in published maps and institutional affiliations.

Copyright: (C) 2021 by the authors Licensee MDPI, Basel, Switzerland This article is an open access article distributed under the terms and conditions of the Creative Commons Attribution (CC BY) license (https:// creativecommons.org/licenses/by/ $4.0 /)$

\begin{abstract}
With the rapid development of modern energy applications such as renewable energy, $P V$ systems, electric vehicles, and smart grids, $D C-D C$ converters have become the key component to meet strict industrial demands. More advanced converters are effective in minimizing switching losses and providing an efficient energy conversion; nonetheless, the main challenge is to provide a single converter that has all the required features to deliver efficient energy for different types of modern energy systems and energy storage system integrations. This paper reviews multilevel, bidirectional, and resonant converters with respect to their constructions, classifications, merits, demerits, combined topologies, applications, and challenges; practical recommendations were also made to deliver clear ideas of the recent challenges and limited capabilities of these three converters to guide society on improving and providing a new, efficient, and economic converter that meets the strict demands of modern energy system integrations. The needs of other industrial applications, as well as the number of used elements for size and weight reduction, were also considered to achieve a power circuit that can effectively address the identified limitations. In brief, integrated bidirectional resonant $D C-D C$ converters and multilevel inverters are expected to be well suited and highly demanded in various applications in the near future. Due to their highlighted merits, more studies are necessary for achieving a perfect level of reducing losses and components.
\end{abstract}

Keywords: renewable energy; bidirectional; resonant converter; soft switching; multilevel converter

\section{Introduction}

The detrimental effect of electricity generation from conventional fossil fuel sources has led to the need to shift to renewable and clean energy, such as solar energy, wind energy, hydropower, and geothermal energy; this has now become more prevalent than ever [1,2]. The energy that the earth receives per hour from the sun is estimated to be equivalent to the whole energy that humans consume in a year [3]. Thus, tapping into this readily available resource should gradually eliminate the dependency on conventional energy sources and help in reducing global warming to ensure a cleaner and safer environment. By using these renewable energy sources as distributed energy resources (DERs), the implementation of costly transmission and distribution systems in hilly and rural regions can be avoided. By operating DERs as standalone renewable energy systems (SARES), the delivery of electric power to remote areas at reasonable costs can be ensured [4]. In the coming years, renewable energy sources, such as photovoltaic $(P V)$ systems, fuel cells $(F C)$, and wind energy farms $[5,6]$, will lead power generation. A major characteristic of $P V$ sources is their low $D C$ voltage, which makes them inappropriate for direct microgrid use. Photovoltaic 
modules are typically connected in series to achieve higher voltages; this demands a huge number of $P V$ components and physical space. Efficient $D C$ - $D C$ converters are required to transform this low voltage to high voltage for better utilization of renewable energy sources. The converter must meet certain requirements, such as low cost, light weight, low voltage switching tension, and high power density [7]. Therefore, $A C-D C / D C-D C$ conversion techniques have gained research attention nowadays for achieving better power conversion efficiency [8]. Figure 1 shows the application of different power electronic converters in renewable energy system applications.

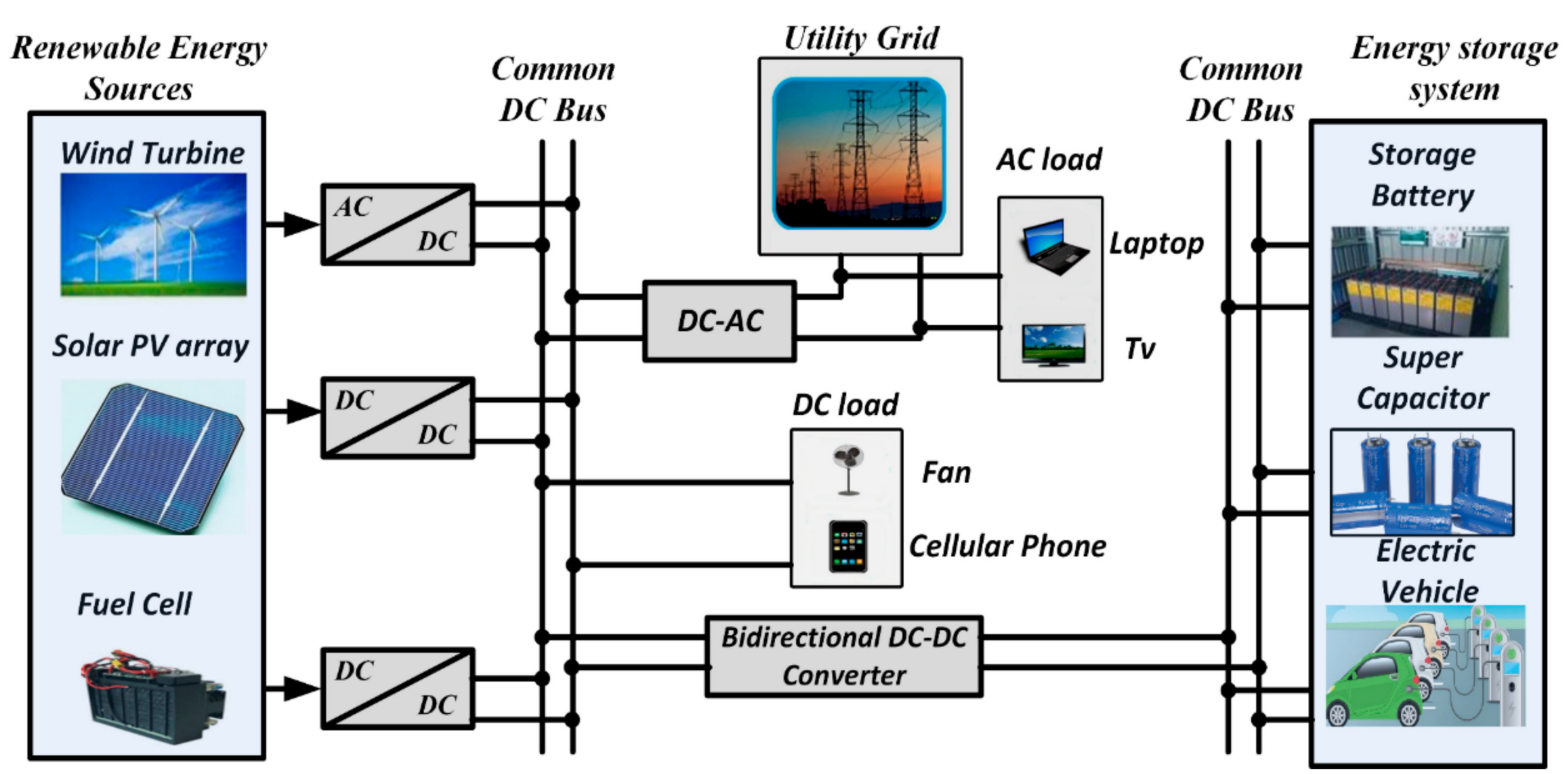

Figure 1. Application of power electronic converters in a renewable energy system.

Many researchers have addressed different types of $D C-D C$ converters for renewable energy applications and storage to improve and enhance efficiency whilst overcoming the weaknesses of converters. $D C-D C$ converters are categorized into three major technologies based on their operation modes, as shown in Figure 2 [9-11]. They are linear mode, hard switching mode, and soft switching mode. The linear mode has features such as simplicity, low noise with good regulation, and quick response. On the other hand, its drawback is low efficiency due to power losses in various working conditions. Hard switching mode converters can be sub-categorized into non-isolated and isolated converters based on galvanic isolation. The buck, boost, buck-boost, and Cuk converters are typical examples of the hard switching mode topologies that are without galvanic isolation (non-isolated) and identified as chopper circuits. However, galvanic isolation (transformer) is necessary for safety causes when the converters are supplied by the utility grid. Power converters $(P C s)$, with their control techniques, help regulate voltages of nodes in microgrids with different types of loads such as resistive, inductive, nonlinear, constant power, or critical loads. However, constant power loads (CPLs) affect the stability of the voltage in the output of PCs and are usually difficult to regulate with traditional control techniques [12,13].

Another type under the switching mode is the isolated converter; this converter utilizes more than one switching method converter, including half-bridge, full-bridge, dual half-bridge, flyback, and push-pull converters. The drawbacks of hard switching mode converters include high electromagnetic interference (EMI), high switching losses, and huge size and weight, which affects the switching frequency. The third classification of $D C$ $D C$ converter is soft switching, also known as resonant converters; these were developed to overcome the issues in hard switching as revealed by several researches, especially related to their industrial applications [14,15]. Soft switching can either be zero current switching $(Z C S)$ or zero voltage switching $(Z V S)$. Compared to liner regulators, these two have better efficiency and ability to work at high switching frequencies, which permit the use of a 
small ferrite transformer core; they can also work in a wider range of $D C$ input voltages compared to linear regulators.

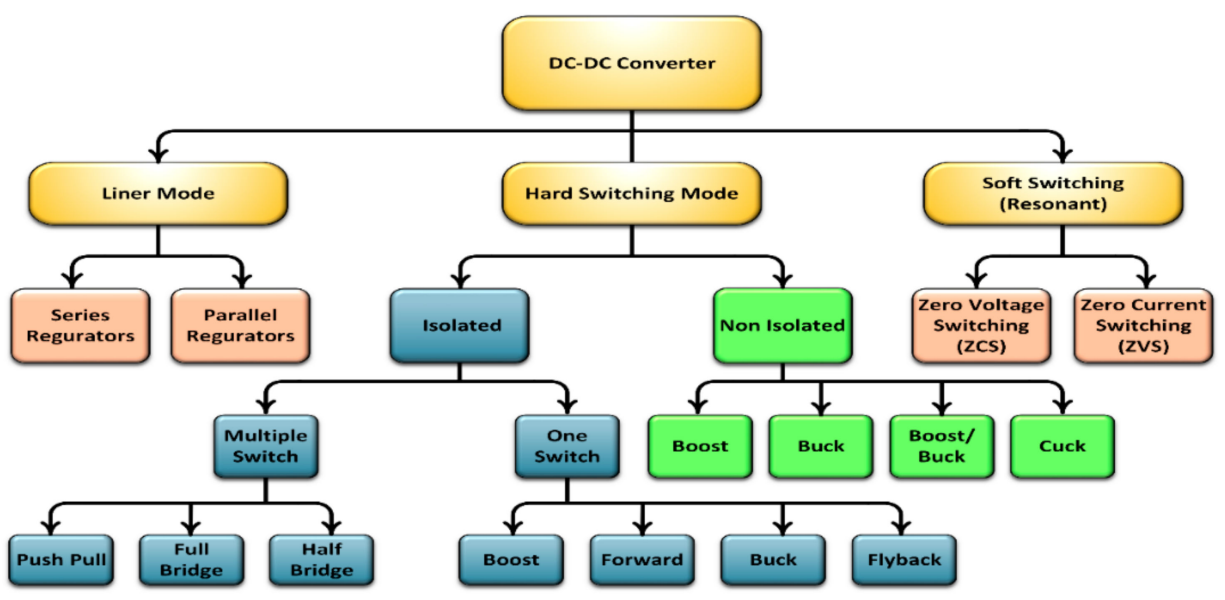

Figure 2. Classification of $D C-D C$ converters [16].

Bidirectional $D C-D C$ converters are receiving much attention for both academic and industrial applications; they are mainly used to maintain the reliability of systems and as an interface between the battery and supercapacitors as storage devices [17]. Bidirectional DC$D C$ power converters are increasingly being used in a variety of applications that demand power flow in both directions. These include, but are not limited to, energy storage systems, uninterruptable power supplies, electric vehicles, and renewable energy systems, to name a few. The classification and different types of bidirectional converters are presented in detail in the following section [18]. Currently, resonant DC-DC converters are the preferred option of power conversion for many low- and high-voltage applications. Resonant $D C-D C$ converters typically contain characteristics that reduce switching losses at the inverter switches and output rectifier diodes, allowing them to operate at higher switching frequencies and yield higher efficiency, resulting in smaller converters. Resonant $D C-D C$ converters come in a variety of topologies, including series resonant $D C-D C$ converters $(S R C s)$, parallel resonant $D C-D C$ converters ( $P R C s)$, and series-parallel resonant $D C-D C$ converters (SPRCs) [19]. Due to their simplicity and popularity, many researchers have worked on and recommended resonant converters in various applications [16,20-22].

In addition to $D C-D C$ conversion, $D C-A C$ conversion is also required to supply $A C$ loads as well as grid integration of $D E R s$. Multilevel inverters are one of the most researched power converter topologies in industrial and residential applications. In recent years, multilevel inverters have received a lot of attention in the applications of medium-voltage and high-power ranges owing to their numerous advantages, and some of the advantages of multilevel inverters over the traditional two-level inverters include lower $E M I$, less harmonic distortion, and lower voltage stress on semiconductor elements. Their drawback is that they require a large number of semiconductor elements. When compared to two-level inverter topologies with the same power ratings, multilevel inverters are more effective in eliminating the harmonic component of voltage and current waveforms. Multilevel topologies are classified into different types, such as cascaded h-bridge, diode-clamped, and capacitor-clamped inverters [23,24]. In applications requiring high-power converters, multilevel inverters are vital. They are also widely used in clean energy sources where they serve as a connection between renewable energy sources (RESs), such as $P V$ modules, and high-power loads [25]. Among the common application areas of multilevel inverters (MLI) are Flexible Alternative Current Transmission System (FACTS) devices, power converters, and reactive power compensation systems for high-power $A C$ motors [25-27]. Apart from individual topologies, recently the hybridization of topologies is becoming popular. For an example, resonant converters are enabled to operate in bidirectional mode for power transfer both ways. Bidirectional resonant converters are relatively easy to integrate 
amongst other components [28,29]. Thus, they are broadly used in battery chargers, supercapacitors, electric vehicles, high-voltage power supply applications, and renewable energy systems [30].

Multilevel inverters are hybridized with $D C-D C$ converters to enable compact stepup $D C-A C$ conversion, and topologies such as multilevel bidirectional converters and multilevel bidirectional resonant converters are proposed. The key targets and purpose of multilevel bidirectional converters are to achieve and meet the requirements of: (i) a remarkable reduction in switching losses, (ii) a reduction in harmonic distortion (HD), and (iii) high efficiency with low component count to provide efficient and convenient size.

This article focuses on different topologies of bidirectional and resonant $D C-D C$ converters, as well as multilevel inverters. The hybrid structures of these converter topologies are also presented. Different attributes, comparisons, advantages, and disadvantages of each topology and their applications are critically analyzed. The challenges and future prospects of the latest converter topologies are also elaborated. The remaining part of this article is organized as follows: Section 2 reviews bidirectional converters, their classification, and comparison between isolated and non-isolated converters. Section 3 explains resonant converter structures and their classifications, while Section 4 focuses on multilevel inverter topologies with respect to diode-clamped, capacitor-clamped, and cascaded topologies. Section 5 highlights the combined topologies of each two of these converters, while Section 6 describes the application of all these converters in grid connection and energy storage systems. The challenges and future perspectives are summarized in Section 7 , while the last section (Section 8) presents the conclusion of this study.

\section{Bidirectional DC-DC Converters}

The continuous flow of power is an important concern when it comes to renewable energy systems; therefore, bidirectional $D C-D C$ converters are employed to interface storage systems with the energy resource and load by reducing or eliminating the fluctuation in the output of renewable energy systems as a result of variations in climate conditions. They are also used between the energy source and motor supplied by batteries [17]. In mediumpower rank devices where familiar and efficient energy storages are supercapacitors and batteries, the energy exchange between the storage device and the other components of the system requires the presence of a $D C-D C$ converter, and such converters must have a bidirectional power flow capability and should have an adaptable control in all operation modes [31-33].

Only one-directional power flow management can be achieved with a conventional buckboost converter when compared with bidirectional power, which can flow in two directions (forward $(F W)$ and backward $(B W)$ ). Bidirectional $D C$ converters $(B D C s)$ are a device for either stepping up or stepping down voltage level; it can facilitate two-directional power flow (both forward and backward power flows). Bidirectional $D C-D C$ converters are mainly used to manage the flow (forward and backward) of power in $D C$ bus voltage where power flow is in both directions, as shown in Figure 1. The conversion of the conventional $D C-D C$ converter into a bidirectional converter can be achieved using a bidirectional switch with a diode, with the current flow in both paths being accepted by anti-parallel with an insulated-gate bipolar transistor (IGBT) or metal-oxide-semiconductor field-effect transistor (MOSFET) employing a controlled switching procedure. Bidirectional DC/DC converters are of two kinds based on existing galvanic isolation between the input and the yield; they are isolated bidirectional $D C(I B D C)$ and non-isolated bidirectional $D C$ $(N I B D C)[34,35]$. The adaptability of the energy storage system can be improved by using a high-frequency isolated $D C-D C$ converter to replace the line-frequency transformer. The circuits of most $D C-D C$ converters are arranged asymmetrically to couple the two $D C$ connections to various voltages, from tens of volts to hundreds of volts [36]. Bidirectional converters have become more popular, as opposed to traditional unidirectional converters, as they permit power flow in both directions. They are mostly used in hybrid electric vehicles (HEVs), electric vehicles (EVs), uninterruptible power supplies (UPS), smart grids, 
renewable energy systems (RESs), and aerospace applications; they are also used in other systems that require batteries [18].

\subsection{Classification of Bidirectional DC-DC Converter}

As mentioned in the preceding section, bidirectional $D C-D C$ converters are of two types-IBDC and NIBDC_-as they been classified in Figure 3, based on galvanic isolation; these are further described below.

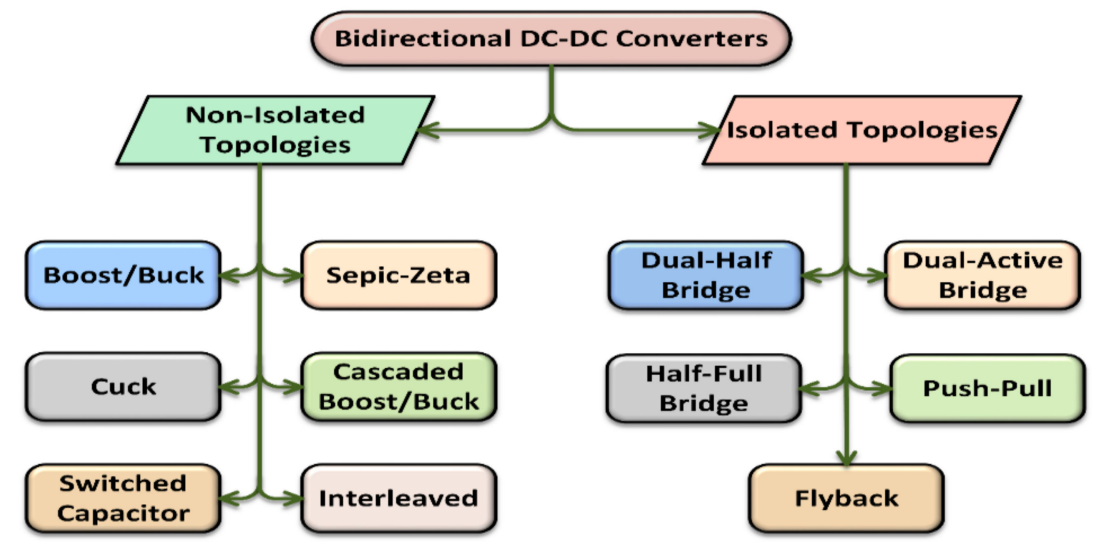

Figure 3. Classification of bidirectional $D C-D C$ converters.

\subsubsection{Non-Isolated Bidirectional DC to DC Converter (NIBDC)}

Due to safety concerns, this type of converter cannot be employed in high-frequency transformers to cater for any electrical isolation. NIBDCs are considerably more efficient in low-power applications due to their ease of control and light weight [37]. Non-isolated bidirectional $D C-D C$ converters have been evaluated in terms of ease of control, simplicity of circuit configurations, low EMI, and high steeping ratio by several researchers $[29,38,39]$.

\section{Bidirectional Buck-Boost Converter}

This type is considered the fundamental circuit of bidirectional $D C-D C$ converters. Figure 4 illustrates the structure of this converter $[17,31]$. It is a combination of the buckboost converter in parallel but moving or oriented in opposite directions. Power flows from the high voltage $(V b)$ side to the low voltage $(V a)$ side (buck approach) and operates in the reverse manner as a boost converter [18]. In the buck mode, switch $Q 1$ is ON by duty cycle control, while $Q 2$ is OFF in this mode. Similarly, when step-down $Q 2$ is ON, $Q 1$ is OFF. Cross conduction can be avoided by setting a dead time between both switches to ensure safe operation [40]. This topology is basic and has noteworthy effectiveness [41].

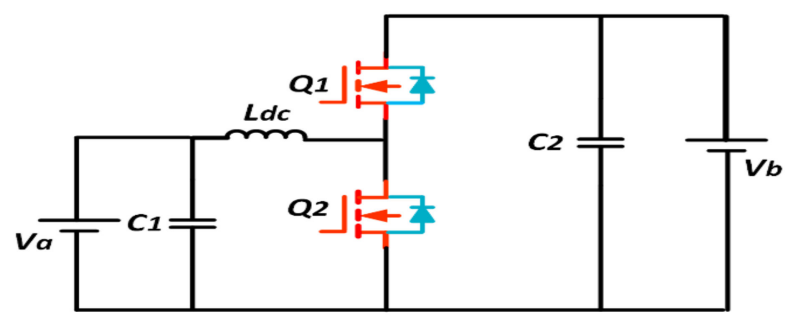

Figure 4. Bidirectional buck-boost converter [18].

\section{Bidirectional SEPIC-ZETA DC to DC Converter}

This topology has two modes of power flow; these are positive and backward modes. In the forward power flow, this converter works as SEPIC, while in the negative mode, the converter works as ZETA. The structure of a SEPIC-ZETA DC-DC converter is shown in Figure 5; it serves in the adjustment of Cuk converters so that their output will not have inverse polarity, as is the case with Cuk converters. The operation of this converter relies on 
both buck and boost techniques [42]; positive power flow is achieved by switching ON Q1 and turning OFF Q2 such that it can work as a buck converter (SEPIC mode). However, in the reverse power flow mode, $Q 2$ is switched OFF so that the system will work as a boost converter (ZETA mode). The use of two inductors, $L 1_{\mathrm{dc}}$ and $L 2_{\mathrm{dc}}$, can reduce the ripple from voltage yield and voltage rating overwork on switches.

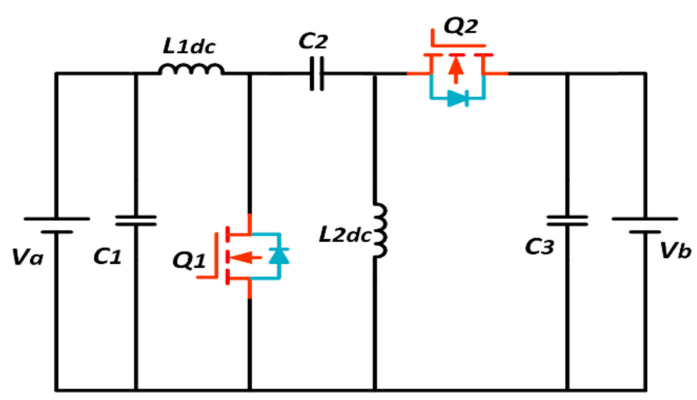

Figure 5. Bidirectional SEPIC-ZETA DC/DC converter [38].

Bidirectional Cuk Converter

By using a MOSFET instead of a diode, the bidirectional Cuk converter is an improvement of the unidirectional Cuk converter, as shown in Figure 6. This converter is a better choice for interfacing supercapacitors and batteries in circuits since it produces less ripple from its output compared to the cascaded buck-boost and bidirectional buck-boost converters [43-45]. Reduced ripple yield current can be achieved by combining $L 1_{\mathrm{dc}}$ and $L 2_{\mathrm{dc}}$ inductors. $Q 1$ acts as the control switch in the positive power flow mode while $Q 2$ is switched OFF and the body diode of switch Q2 serves as the main diode. Contrarily, $Q 2$ serves as the active switch in the backward power flow while $Q 1$ is switched OFF, leaving the body diode of switch $Q 1$ to work as the primary diode.

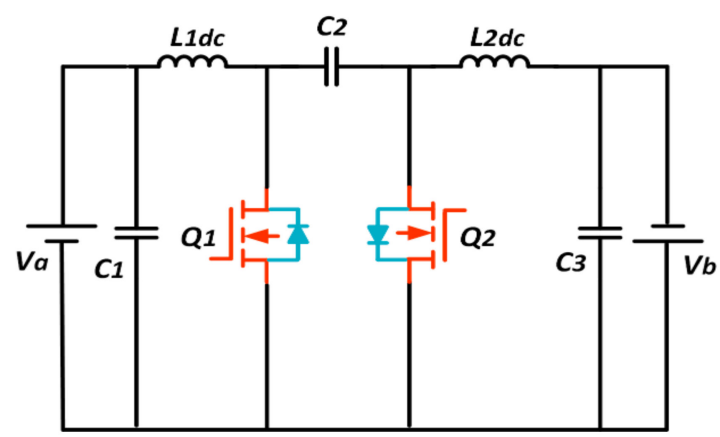

Figure 6. Bidirectional Cuk converter [38].

\section{Cascaded Bidirectional Buck-Boost Converter}

Figure 7 displays another converter topology that can be achieved by cascading a buck converter with a boost converter. This topology is the outcome of cascading two buck-boost $B D C$ [18]. Each of the four quadrants is conceivable with this topology; thus, this topology works in buck and boost modes in both directions. The four-quadrant activity of this topology makes this topology generally adaptable. Despite this, it has some weaknesses, such as the use of a higher number of switches, which causes higher switching losses; it also relies on complex control algorithms and experiences additional operating losses due to the inverse diode recovery $[38,46,47]$. In ESSs, the cascaded buck-boost $(C B B)$ converter is frequently utilized. In comparison to the combined half-bridge $(C H B)$ converter, the $C B B$ converter is smaller and more efficient at converting power because it only utilizes one inductor [48]. 


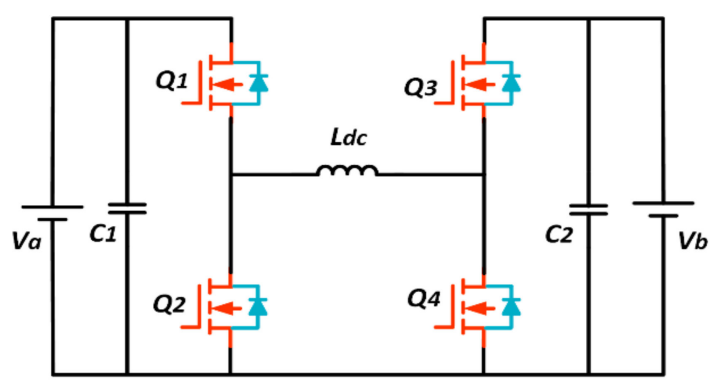

Figure 7. Cascaded bidirectional buck-boost converter [48].

\section{Switched Capacitor Bidirectional DC-DC Converter}

In bidirectional $D C-D C$ converters, capacitor exchange is achieved by employing integrated circuits (ICS) in DC-DC converter circuits (see Figure 8). This integration of ICs is less complex due to the lack of any need for magnetic equipment in the non-isolated $D C-D C$ converter. Due to the huge number of inactive elements that account for electromagnetic interfacing $(E M I)$, such converters suffer from high ripple at the output. This issue can be prevented by employing a control plan, for example, voltage and current control techniques, but this can compromise the intricacy of the system and increase the related cost $[18,49]$.

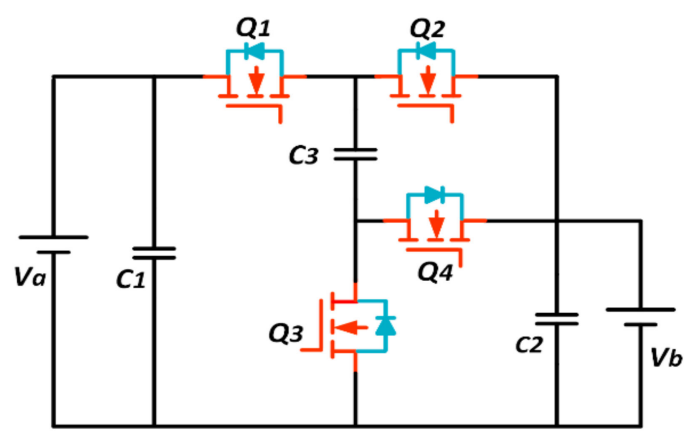

Figure 8. Switched capacitor of bidirectional DC-DC converter [18].

\section{Interleaved Non-Isolated Bidirectional DC-DC Converter}

This topology involves the combination of two or more converters in parallel; it has a relative phase shift of $360^{\circ} / \mathrm{n}$. Some of the advantages of interleaved converters include solving the issue of output current ripples, current splitting $(I / n)$, better system productivity, higher power density, and better thermal capacity. Owing to the current splits in the parallel routes, there is a lower rate of conduction losses, and fewer switches are needed. The presence of the interleaving strategy reduces the current and voltage ripple at the input of the $D C-D C$ converter without increasing the switching losses; thus, the efficiency of the system is higher [50]. There is only one type in this topology, which is a two-phase interleaved non-isolated bidirectional $D C-D C$ converter; it comprises two output stages, with $180^{\circ}$ out of phase. A simplified two-phase interleaved DC-DC converter circuit is shown in Figure 9. Note that the interleaved half-bridge converter is the commonly used topology $[31,51,52]$ as it offers better voltage transformation even when the size of the converter is small; it also reduces switching losses. However, this converter has some drawbacks, such as high cost as a result of the higher number of elements and its complex control technique [53]. 


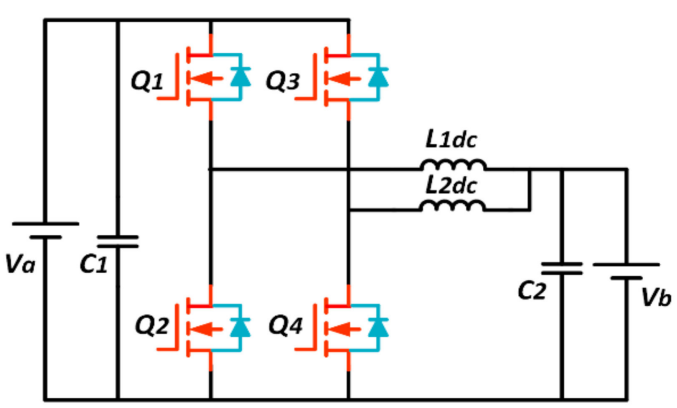

Figure 9. Two-phase interleaved half-bridge bidirectional DC/DC converter [54].

\subsubsection{Isolated Bidirectional DC-DC Converters (IBDCs)}

There are no secure galvanic isolation standards in the non-isolation $B D$ converter; hence, most applications use IBDCs rather than NIBDCs. IBDCs rely on a great frequency transformer to offer galvanic isolation. In numerous applications and with regard to overburden for the safety of the source, galvanic isolation is vital, in addition, to reduce commotion and voltage coordination between conditions [55]. Most IBDCs have similar structures, as shown in Figure 10. This converter works in two stages: great frequency switching by the $D C-A C$ converter and the utilization of a high-frequency transformer to maintain the galvanic isolation between two sources, as well as the utilization of transformers to coordinate the voltage between various stages for the best possible plan and enhancement of various stages [31,56]. Isolated bidirectional $D C-D C$ converters with a basic structure were proposed by [31] to function as a flexible interface for power processing between the energy storage system and the other system components.

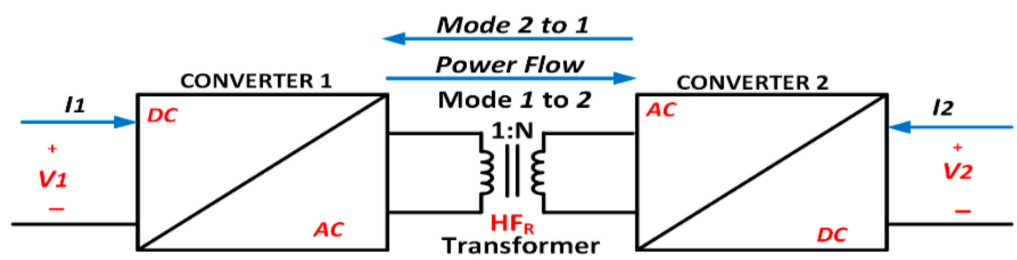

Figure 10. Structure of IBDC (BASIC) [31].

The IBDC has some benefits, such as having no need for active or passive elements in soft switching. Secondly, the structure of the transformer is simple; therefore, maintenance and designing tasks are also simple. Additionally, both parts face the same issue of stresses in the switch currents. This approach also relies on the average current control method or peak current mode control. The absence of extra inactive components ensures quicker dynamic conduct. On the other hand, this converter has drawbacks, such as losing soft switching in light load conditions, and this control is sensitive to a slight variety of flux, particularly when bus voltages are high. An additional weakness is that currents flowing in $D C$ buses hold great ripple content; this demands fitting filtering circuits, which makes the circuit complex [56,57]. An isolated converter has many topologies, such as the push-pull $I B D C$, forward $I B D C$, fly-back $I B D C$, dual half-bridge $I B D C, C u k I B D C$, and dual active full-bridge $I B D C$ [58-61]. The efficiencies of the full-bridge and half-bridge topologies endear them to many applications $[62,63]$.

\section{Dual Half-Bridge (DHB) IBDC}

One of the most commonly used isolated bidirectional $D C-D C$ converters is the dual half-bridge $(D H B)$ converter (see Figure 11) [18,64]. Isolated $D H B$ bidirectional $D C-D C$ converters have great power density, soft switching, and simplicity in control; thus, they are suitable for $E V$ application. They have an approximate efficiency of 92 to $94 \%$; they have two sides-a low and a high voltage side-where voltage is fed to the half-bridge converter on the right side ( $A$ side) and modified current feeds the half-bridge on the low 
voltage side. They are also called boost half-bridge ( $B$ side) and are usually on the lower side since they consist of a capacitor or battery $D C$ energy source in which a low current ripple is preferred [65].

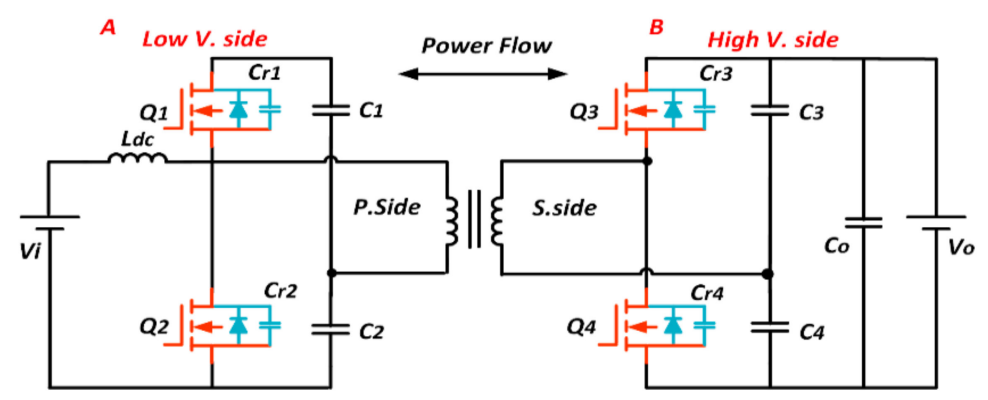

Figure 11. Isolated DHB bidirectional DC-DC converter [31].

Additionally, the battery sector of the circuit contains an inductor $L_{\mathrm{dc}}$ and two halfbridges, each on either side of the main transformer. For each switching device, there is a small parallel capacitor that enables soft switching. The boost style working mode of the circuit is established when there is power flow from the low to high voltage side (HVS); this maintains the HVS voltage at the expected high level. Contrarily, the circuit works in the buck mode when recharging the battery from any RES. The HVS switch is performed with IGBTs while the low voltage side (LVS) switch is performed with MOSFETs. Note that the inductor and the LVS half-bridge are arranged uniquely, with the LVS half-bridge having dual roles, which include (i) serving as a boost converter to improve voltage; and (ii) serving as an inverter to improve the frequency of the $A C$ voltage [66]. More current is drawn by the LVS boost converter from the load voltage resource when compared to the full-bridge voltage source inverter. A boost function is obtained by merging the LVS half-bridge and the inductor.

\section{Dual Active Full-Bridge (DAFB) IBDC}

One of the most common topologies is to employ back-to-back bidirectional techniques that are isolated by a high-frequency transformer. Back-to-back converters can be voltage-fed or current-fed, half-bridge, or full-bridge configurations. Figure 12 illustrates the configuration of the full-bridge $I B D C$ - $D C$ converter, which utilizes two full-bridge techniques in both sides of the transformer. The power transmission of bidirectional converters is proportional to the number of switches, and the high productivity and high power density of this topology make it appealing to hybrid energy systems [67].

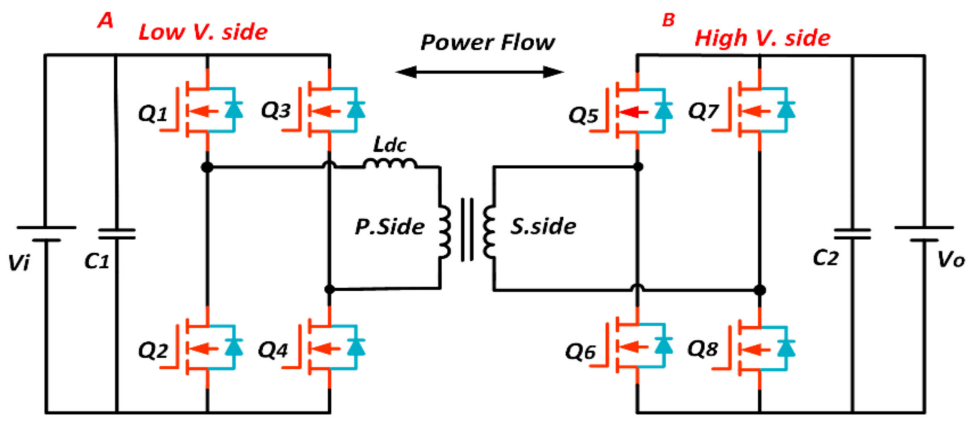

Figure 12. Isolated DAFB bidirectional DC-DC converter [31].

The above description of power capacity with switches generally suggests that the $D A F B-I B D C$ has the greatest power capacity (efficiency of around $95 \%$ ); thus, this converter is well suited for high power applications with similar hybrid energy systems. In this structure, full-bridge is employed at either end of the isolation transformer, while a soft switched phase shift approach is used to implement the control. To provide an approximate 
square wave $A C$ voltage, in every converter, the diagonal switching couples are switched on at once, with fifty percent duty cycle (excluding a small dead time) and with the two legs of the crossways transformer terminal having a $180^{\circ}$ phase shift. An important factor, represented as $\varphi$ (Phi), denotes the observed phase shift between the two $A C$ voltages; it is important in deciding the quantity and direction of power transfer between the $D C$ buses. This parameter can be modified to achieve a fixed frequency activity with full control [68]. Figure 13 illustrates the contrast between half- and full-bridge topologies. The half-bridge topology has all the switch-related voltage stresses as twice the $D C$ input voltage $\left(2 V_{d c}\right)$, while the current stress and load current $I_{a c}$ are equivalent. In the full-bridge topology, each switching device relies on the voltage stress and is equivalent to the DC input voltage $\left(V_{d c}\right)$, while the current stress is equivalent to the load $I_{a c}$. Figure 13 shows the total device rating $(T D R)$ in half- and full-bridge topologies. For the full-bridge topology, the TDR is calculated as:

$$
T D R_{F}=V_{d c} \times I_{a c} \times 4(\text { devices })=4 \times P_{o}
$$

where $P_{o}$ is the output power. Meanwhile, the TDR of the half-bridge topology is estimated as:

$$
T D R_{F}=2 V_{d c} \times I_{a c} \times 2(\text { devices })=4 \times P_{o}
$$

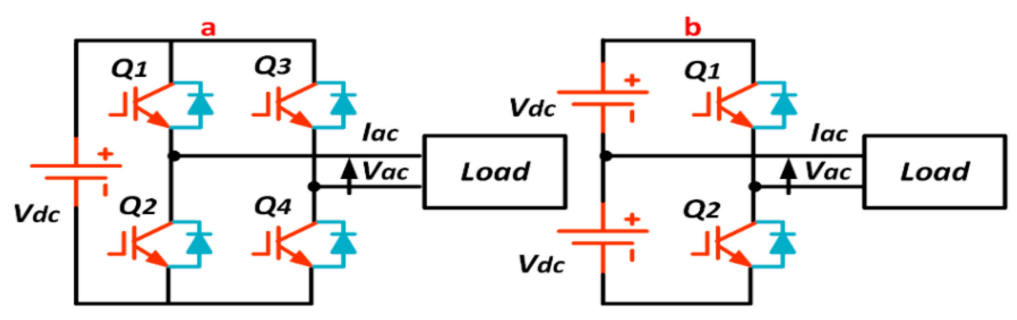

Figure 13. Comparison of (a) full-bridge topology and (b) half-bridge technique [69].

Hence, the TDR is the same for the dual full-bridge and dual half-bridge topologies at the same output power. Additionally, it is true that half-bridge devices are exposed to twice the DC input voltage; this is beneficial for both $E V s$ and $H E V s$, as well as for fuel cell usage due to the low value of the $D C$ input voltage (12 Volt battery). The dual half-bridge topology also uses fewer devices compared to the full-bridge topology.

\section{Half-Bridge-Full-Bridge Bidirectional DC-DC Converter}

Considering dual active bridge, in the case of a UPS design, an isolated bidirectional $D C-D C$ converter was proposed, which uses a voltage-fed half-bridge topology in the primary side and a voltage-fed full-bridge topology in the secondary side of the transformer (see Figure 14) [18]. It enables easier control requirements than $D A B$ because of the lower number of switches. Particularly, it is well suited to the integration of a two-switch buck-boost converter in the half-bridge side for obtaining a complete UPS topology. Other variations of this configuration have been proposed, such as a full-bridge-half-bridge bidirectional $D C-D C$ converter paired with impedance networks to improve performance [70].

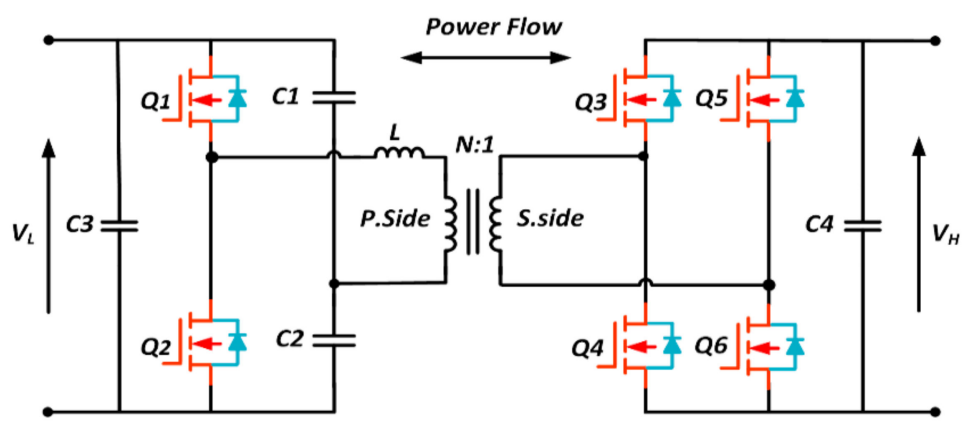

Figure 14. Isolated half-bridge-full-bridge bidirectional DC-DC converter [18]. 


\section{Bidirectional Flyback}

In the case of the magnetic isolation requirement, the well-known flyback converter is realized when a transformer replaces the inductor of the buck-boost converter. A bidirectional isolated buck-boost converter can be constructed using the bidirectional evolution technique in non-isolated topologies, as shown in Figure 15. The gain of the converter in forward power flow is obtained by applying the volt-second and chargesecond balancing, which is the same as the voltage gain ratio of the flyback converter as expected. It is worth noting that the transformer design technique must be considered, and a voltage clamp snubber is required to control the flyback transformer's leakage current [71].

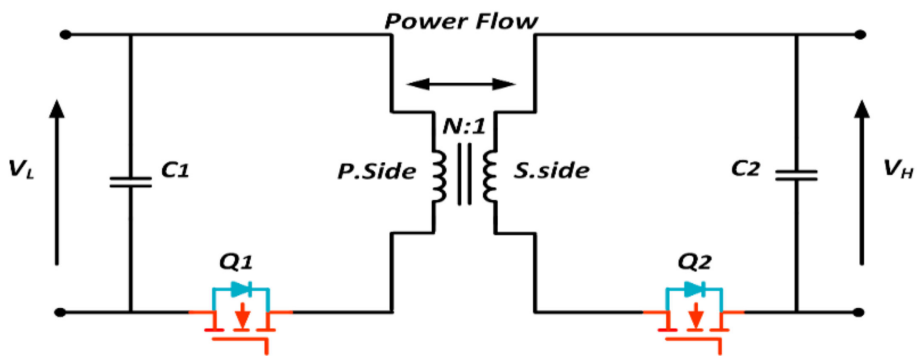

Figure 15. Isolated bidirectional flyback [72].

\section{Push-Pull Bidirectional DC-DC Converter}

Based on the unidirectional push-pull converter, the bidirectional push-pull converter (see Figure 16) was suggested in order to allow power to flow in both directions. Same as unidirectional push-pull converters, bidirectional push-pull converters use a multiwinding transformer to convert the power. A three-phase bidirectional push-pull converter was also proposed to run this approach in high-power applications [73].

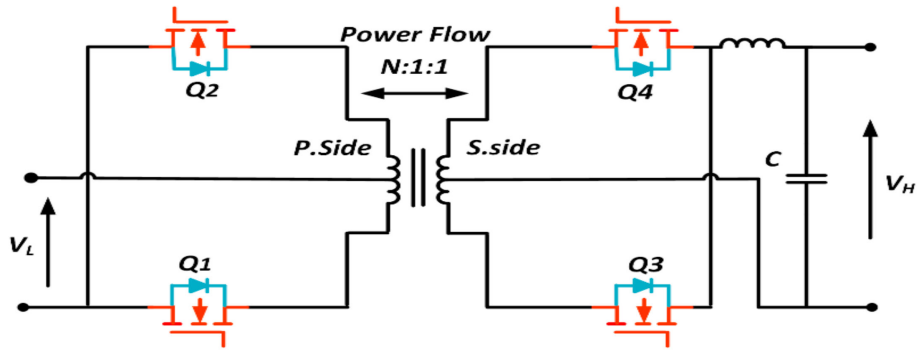

Figure 16. Isolated push-pull bidirectional DC-DC converter [18].

\subsubsection{Comparison of NIBDCs and IBDCs}

In this section, a comparison between the two main general groups of configurations, isolated and non-isolated topologies, was made in terms of the advantages and disadvantages, as illustrated in Table 1.

Table 1. Pros and cons of NIBDC and IBDC bidirectional DC-DC converters. Type

(1) Symmetrical structure.

(2) The ripple current is low on both sides.

(3) It has short circuit safety.

NIBDC (4) It can operate with a wide range of voltages and different voltage levels.

(5) It uses only two switches to simplify the circuitry of the driver and to reduce the driving power.

\section{Disadvantages}

(1) Works only in one direction, either in buck mode or in boost mode.

(2) When the voltage ratio is raised, the design (structure) is impractical.

(3) There is less galvanic isolation between the two sides. 
Table 1. Cont.

\begin{tabular}{|c|c|c|c|c|}
\hline Type & & Advantages & & Disadvantages \\
\hline$I B D C$ & $\begin{array}{l}\text { (1) } \\
(2) \\
(3) \\
(4) \\
(5)\end{array}$ & $\begin{array}{l}\text { There are almost equivalent current switch stresses on } \\
\text { both sides. } \\
\text { Soft switching can be achieved without the need for active } \\
\text { or passive components. } \\
\text { Has a simple construction that simplifies the process of } \\
\text { design and maintenance. } \\
\text { Has a fast-dynamic action feature due to the lack of } \\
\text { additional passive components. } \\
\text { Has average current mode control or peak current } \\
\text { mode control. }\end{array}$ & $\begin{array}{l}\text { (1) } \\
\text { (2) }\end{array}$ & $\begin{array}{l}\text { Under light load conditions, the } \\
\text { converter might lose soft switching. } \\
\text { The current that flows in } D C \text { buses } \\
\text { contains a high ripple content, which } \\
\text { requires suitable filtering circuits, } \\
\text { complicating the circuit. } \\
\text { This control is extremely sensitive to } \\
\text { slight flux variation, particularly when } \\
\text { bus voltages are high. } \\
\text { A relatively high number of components, } \\
\text { leading to greater driver volume, gate } \\
\text { losses, and cost, in contrast to topologies } \\
\text { with low switch count. }\end{array}$ \\
\hline
\end{tabular}

\section{Resonant Converter Families}

Studies have been devoted to resonant converters since the 1980s to meet most of the industrial requirements, such as efficient energy conversion, higher power density, smooth waveforms, etc. Initially, the idea was to integrate resonant tanks into converters to generate oscillatory voltage and/or current waveforms that will ensure ZVS or ZCS conditions for power switches [23]. To reduce switching costs and current and voltage pressures as well as EMI, soft-switching strategies are introduced. The switching frequency can be increased by soft-switching conditions, and thus the size and volume of the converter could be decreased. Soft-switching converter topologies are considered an improvement or enhanced generation of hard-switching types [74-77]. Throughout the 1990s, new generations of soft-switching converters had been created, which integrate the advantages of traditional PWM converters with resonant converters. Compared to traditional PWM converters, soft-switching converters have moving waveforms except for the smooth nature of the rising and falling waveform edges, which are devoid of transient spikes. New softswitching converters usually use resonance in a controlled style, unlike resonant converters. To create ZVS and ZCS conditions, resonance will occur just before and during turn-on and turn-off operations. They also act as conventional PWM converters [23].

\subsection{Structure of Resonant Power Converter}

As shown in Figure 17, the structure of a resonant converter consists of three stages $[16,26,78,79]$; the first stage is the control switching network (CSN), the second step is the resonant tank network $(R T N)$, and the third is the network of the rectifier with a low-pass filter (DR_LPF).

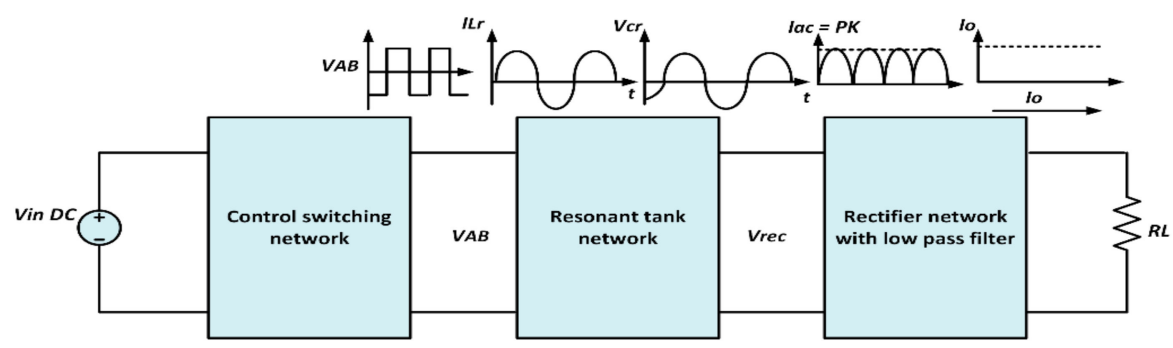

Figure 17. Structure of resonant converters [16].

Each stage is assigned a specific task to accomplish the major goal of the resonant converter; for instance, the $D C$ source enables the quick mode switching of the controlled switching network (CSN) based on the working frequency to generate the output voltage to be fed into the next step. To reduce THD in the second stage, sinusoidal voltages and 
current signals are generated using the stage of the high-frequency resonant tank network $(R T N)$ that consists of two or more reactive components [80]. This stage will be defined by the frequency selective network as energy buffering between the load and the CSN. The impedances of both inductance and capacitance are the same in resonance conditions particularly, which will produce the resonant frequency. Then, a rectifier network rectifies and filters the incoming signal, then passes the filter to generate the correct $D C$ output voltage [81].

\subsubsection{Control Switching Network (CSN)}

The CSN is a setup that facilitates the conversion of $D C$ power into $A C$ power. The most familiar switching networks are full- and half-bridge as their utilization is dependent on the required power. The full-bridge inverter is mainly used in high-power applications, while half-bridge inverters can offer only $50 \%$ of the active switch input voltage. As the latter has low levels of voltage transition, it is ideal for high input voltage applications [82]. Most times, resonant power converters and conventional DC-DC converters seem alike in terms of achieving soft switching and the chance of working at a high switching frequency. This is due to the possibility of $D C$ - $D C$ power conversion from $D C$ to $A C$ using inverters. The $A C$ can either be stepped up or down using an electromagnetic component, which then goes through a rectifier network to be supplied as $D C$ power to the load. Typically, resonant converters are employed with full- or half-bridge inverters, together with each full-bridge or center-stapled rectifier $[83,84]$. The $C S N$, as depicted in Figure 18, can generate a square waveform voltage $V_{S}(t)$ (Volt) of the switching frequency $F_{S}\left(\omega_{S}=2 \pi \mathrm{fs}\right)$, as represented by the Fourier series in Equation (3). Considering the response of the resonant tank that has been noted to overpower the basic component fs of the voltage waveform $V s(t)$, the infinitesimal response exhibits harmonic frequencies $n f s, n=3,5,7, \ldots$ Therefore, the power that corresponds to the basic voltage waveform $V s(t)$ component is propagated to the resonant tank, as shown in Equation (4). This basic component is a sinusoidal waveform of peak amplitude equal to $(4 / \pi)$ times the $D C$ source voltage. The basic component is in the same phase as the initial waveform.

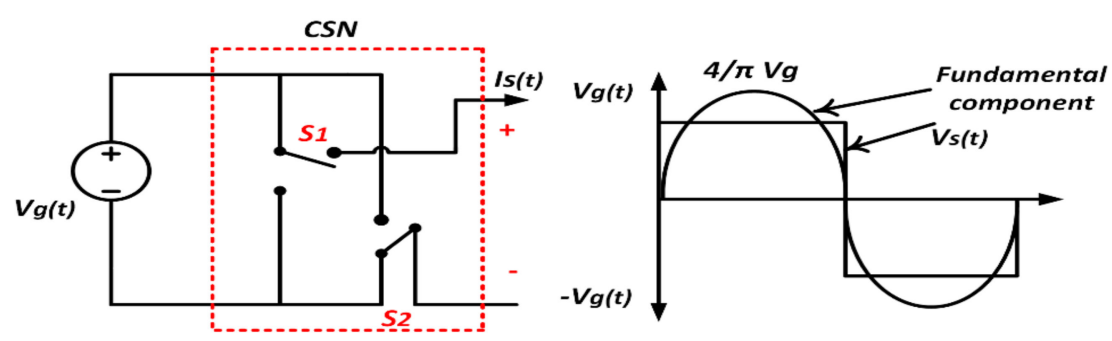

Figure 18. Equivalent circuit of CSN [16].

Turning ON S1 produces a positive sinusoidal switched current $(t)$, while the negative version is produced by turning OFF $S 2$ since the two switches work at the same time and its peak $I s_{1}$ amplitude with phase is equivalent to $\varphi s$. In the meantime, DC to CSN input current is obtained by dividing the sinusoidal switched current over half the switching duration, as expressed in Equation (5) [9,85,86].

$$
\begin{gathered}
V_{s}(t)=\frac{4 V_{g}}{\pi} \sum_{n=1,3,5, \ldots n} \frac{1}{n} \sin \left(n \omega_{s} t\right) \\
V_{s 1}(t)=\frac{4 V_{g}}{\pi} \sin \left(n \omega_{s} t\right) \\
i_{S}(t)=I_{s 1} \sin \left(\omega_{s} t-\varphi_{s}\right) \\
I_{\text {input }}=\frac{2}{T_{s}} \int_{0}^{\frac{T_{s}}{2}} i_{s}(t) d t=\frac{2}{\pi} I_{s 1} \cos \left(\varphi_{s}\right)
\end{gathered}
$$




\subsubsection{Resonant Tank Network (RTN)}

The second stage of the resonant converter is a resonant tank, also termed a resonant circuit. It is considered one of the most critical parts of a resonant power converter. This network contains an inductive and capacitor $(L C)$ circuit (reactive element) that stores electricity, which oscillates with the frequency of the resonant circuit. The movement of energy between the capacitor yields resonance for the inductor in the $L C$ circuit. The electromagnetic frequency is beneficial in various applications, which is generated by the repetitive back and forth electrical energy movement between a fully charged inductor and a capacitor (for instance, in telecommunications technology). In addition, the tank can be charged to a particular resonant frequency by arranging the values of the reactive component. There are various types of RTNs, all of which can be categorized by three major factors $[87,88]$. The first classification is based on the correlation method of the tank elements, such as a series resonant converter (SRC), parallel resonant converter $(P R C)$, and series-parallel resonant converter $(S P R C)$ [89], as shown in Figure 19. The second type is based on the number of two components of the reactive elements (the number of the transfer function order). For the third type, the categories are based on the structure of a single element or resonant tank with multiple elements [86,90].

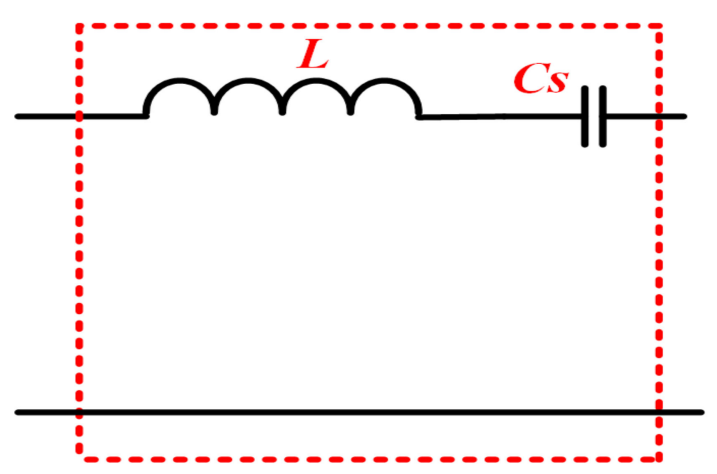

(a)

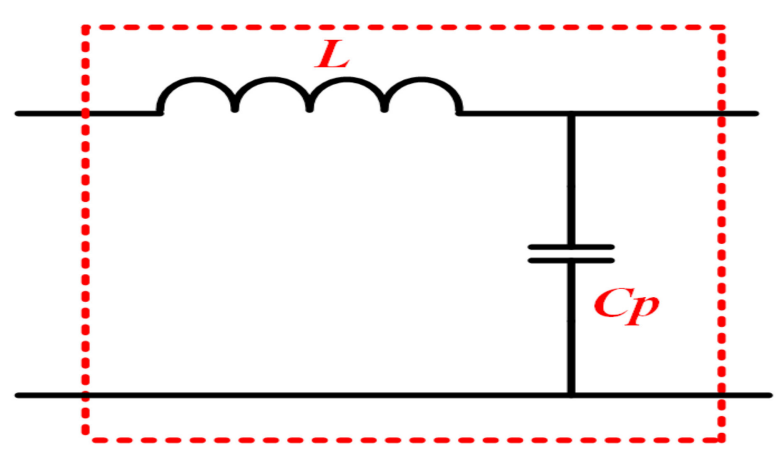

(b)

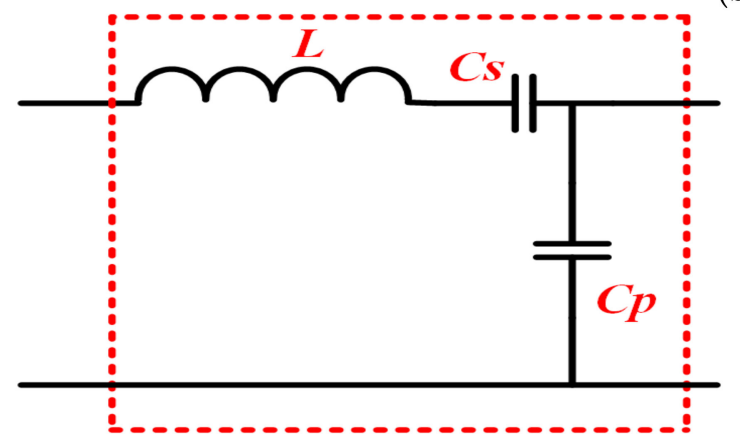

(c)

Figure 19. Several types of resonant tank networks: (a) Series resonant network; (b) Parallel tank network; (c) Series-Parallel tank network [10].

The third classification has two, three, and multi-element resonant tanks. There are several resonant power converter topologies with two elements (see Figure 19), but types a and $b$ are regarded as second-order resonant tanks. As a result of their basic analysis, they are the most common and simplest topologies. Some RTNs are only suitable for the voltage sources, while others are good for the current source. In some cases, SRCs and PRCs are not ideal for use in certain applications, such as in contactless energy transfer devices [91] and high-voltage applications [16].

The development of third-order resonant tanks was conceived as a solution to the problems of the two-component (two-element) RTN; a third element was added to the two-element resonant network to create a three-element resonant network. It can be viewed 
as a combination of the strengths of the two most popular $S R C$ and $P R C$ resonant elements, ignoring their weaknesses. There are thirty-six separate third-order RTN tanks [80,89,92]; some of them consist of two capacitors and one inductor, while others are opposite shaped, as shown in Figure 20a-d. Three-element $R T N$ resonant converters have been widely used in many industries, such as in $L L C, L C C, C L L, L C L$, and hybrid series-to-parallel resonant converters (RCs) [93-96]. LLC and LCC are the commonest forms of third-order RTN converters. For the $L L C R T N$, they are considered as three-element parallel $R C$ s because they exhibit the features of the series resonant converter $R C$ by integrating a parallel inductor that is placed before loading.

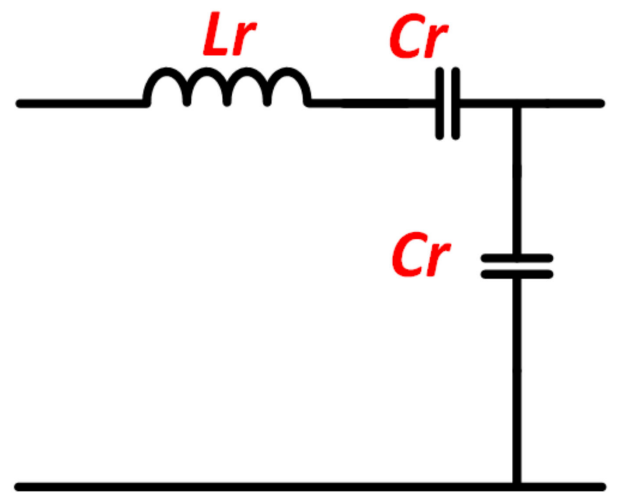

(a)

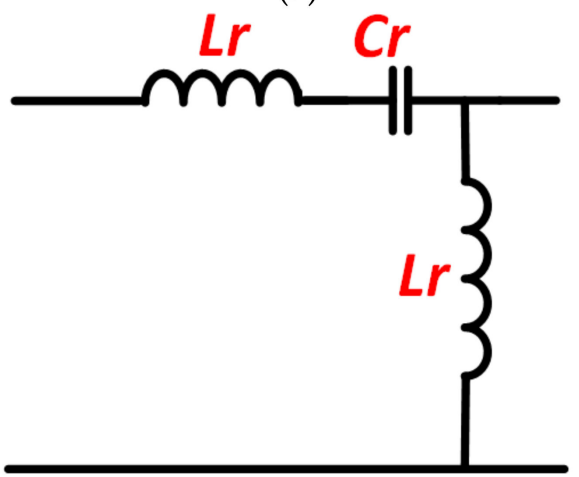

(c)

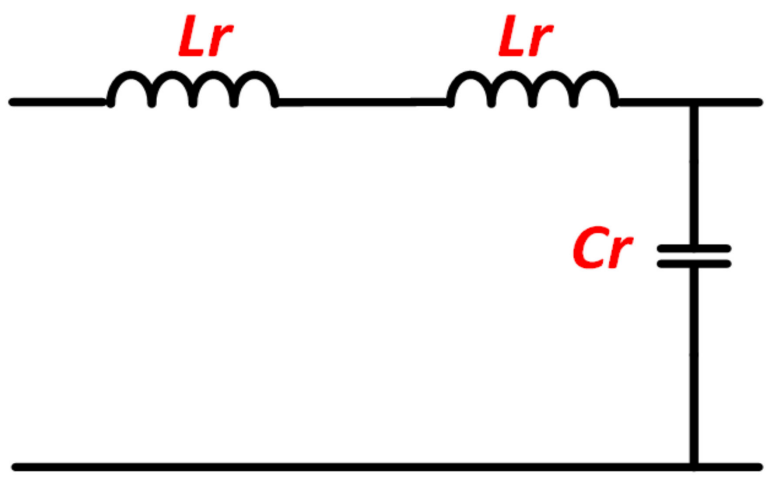

(b)

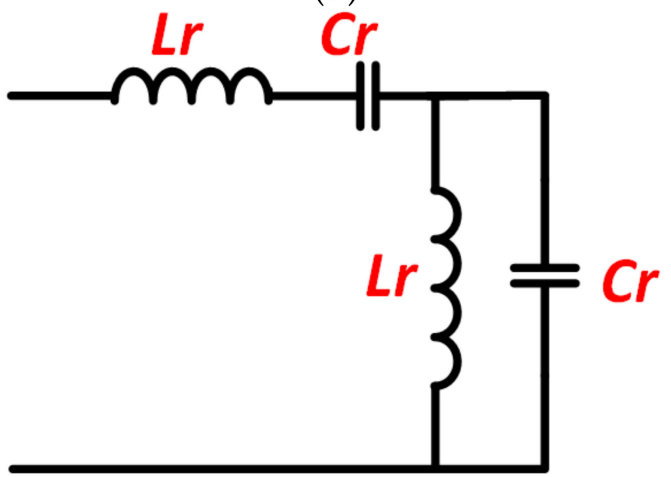

(d)

Figure 20. Three-element and four-element resonant tank network topologies: (a) LCC; (b) LLC; (c) LCL; (d) LCLC [80].

Having four or more elements, as shown in Figure 20d, means the tank is a multielement resonant tank. Generally, the resonant tank relation exists beyond the same number of $R T N$ elements. The relationship between various tank orders indicates that a resonant tank network with multiple elements is equivalent to a lower number of tank elements [89].

\subsubsection{Rectifier Network with Low-Pass Filter}

$D R-L P F$ is mainly employed to resolve and filter the $A C$ waveform as the last stage of the process of the structure of the resonant network converter, after generating sinusoidal current and voltage waveforms by the $R T$ network, to attain the required $D C$ output waveform. There have been many studies on resonant power converters that considered the $D R-L P F$ as a center-tapped or full-bridge rectifier. The high voltage stress on the diodes restricts the practical suitability of center-tapped rectifiers; therefore, a low-pass channel has been preferred for two instances of capacitance or inductance [86,97,98].

- Diode rectifier network with capacitive low-pass filter (DR-LLPF): The evaluation of the $D R$ action when entering the current $i_{R}(t)$ can serve as a basis for testing the corresponding circuit of DR with a capacitive output filter and in-parallel load resistor; this is expressed in Equation (7) due to the series correlation [10]. 


$$
i_{R}(t)=I_{P} \sin \left(\omega_{s} t-\varphi_{s}\right)
$$

Consequently, this current $i_{R}(t)$ is rectified by $D R$, as described in Figure 21. Due to the condenser $C_{f}$ filtering operation, only the $D C$ portion flows into the load, generating the current $I o$ and the related $D C$ voltage $V o$. The $D C$ portion must be equivalent to the current Io at a steady state. Voltage $V_{R}(t)$ at the $D R$ input can be obtained by noting that the conducting diodes of the $D R$ change when current $i_{R}(t)$ crosses null. The value of $V_{R}(t)$ is equal to $V o$ when $i_{R}(t)$ is positive, and equal to $-V_{o}$ at negative $i_{R}(t)$ [10].

$$
\begin{gathered}
V_{R}(t)=\frac{4 V_{o}}{\pi} \sum_{n=1,3,5, \ldots n} \frac{1}{n} \sin \left(n \omega_{s} t-\varphi_{s}\right) \\
V_{R 1}(t)=\frac{4 V_{o}}{\pi} \sin \left(\omega_{s} t-\varphi_{s}\right) \\
I_{\text {out }}=\frac{2}{T_{s}} \int_{0}^{\frac{T_{s}}{2}} i_{R}(t) d t=\frac{2}{\pi} I_{R}
\end{gathered}
$$

- $\quad$ Diode rectifier with inductive low-pass filter (DR-CLPF) (Figure 22): Here, a sinusoidal voltage provides the $D R$, and the $i_{R}(t)$ input current exhibits a square waveform that is equivalent to $\left(-I_{0}\right)$ when $V_{R}(t)$ is negative and $\left(+I_{0}\right)$ when $V_{R}(t)$ is positive. Since the $D R$ 's conductive diodes are adjusted when $V_{R}(t)$ voltage passes 0 , the current $i_{R}(t)$ basic component $i_{R 1}(t)$ is in phase with $V_{R}(t)[10,16]$.

$$
\begin{gathered}
V_{R}(t)=V_{P} \sin \left(\omega_{s} t-\varphi_{s}\right) \\
i_{R}(t)=\frac{4 I_{O}}{\pi} \sum_{n=1,3,5, \ldots n} \frac{1}{n} \sin \left(n \omega_{s} t-\varphi_{s}\right) \\
i_{R 1}(t)=\frac{4 I_{o}}{\pi} \sin \left(\omega_{s} t-\varphi_{s}\right) \\
V_{O}=\frac{2}{T_{s}} \int_{0}^{\frac{T_{s}}{2}} V_{R}(t) d t=\frac{2}{\pi} V_{R}
\end{gathered}
$$

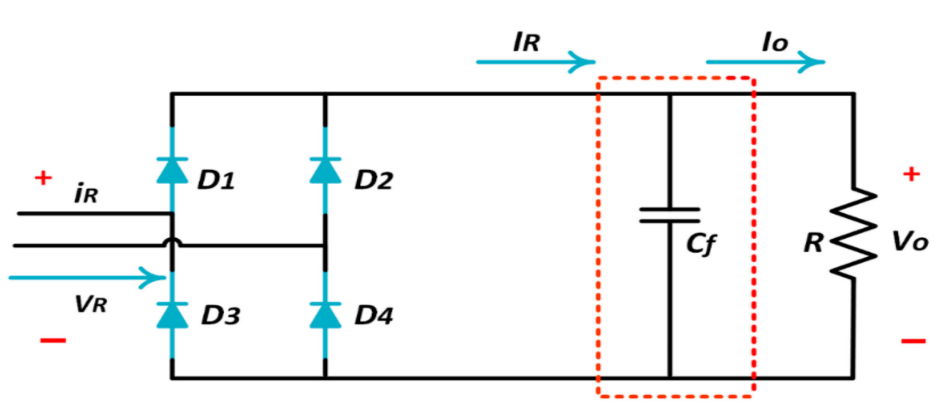

Figure 21. Diode rectifier with capacitive output filter [10].

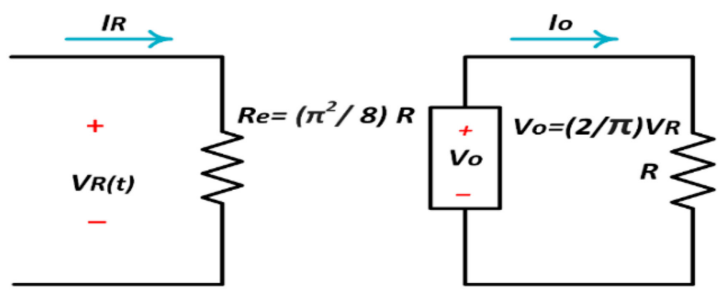

Figure 22. DR equivalent circuit with inductive output filter [10]. 


\subsection{Classification of Resonant Converter}

Resonant converters are classified into three main categories, which are conventional, quasi, and multi-resonant converters, as shown in Figure 23. Conventional resonant converters can be classified into two categories: phase-shift modulated and load resonant converters ( $L R C s)$. The other type, quasi-resonant converters $(Q R C s)$, is considered as a combination of resonant and PWM converters, where the underlying principle is to replace the power switch with a resonant switch [79]. Studies by $[16,80,99,100]$ presented brief and useful explanations about quasi-resonant converters (QRCs), as well as different types of multi-resonant converters that have been projected to overcome the weaknesses of $Q R C$. It should be noted that two resonant capacitors with a resonant inductance (called a multi-resonant network) can be used to achieve zero voltage switching [86]. The following subsections elaborate different conventional resonant converters, including series, parallel, and series-parallel load resonant converters.

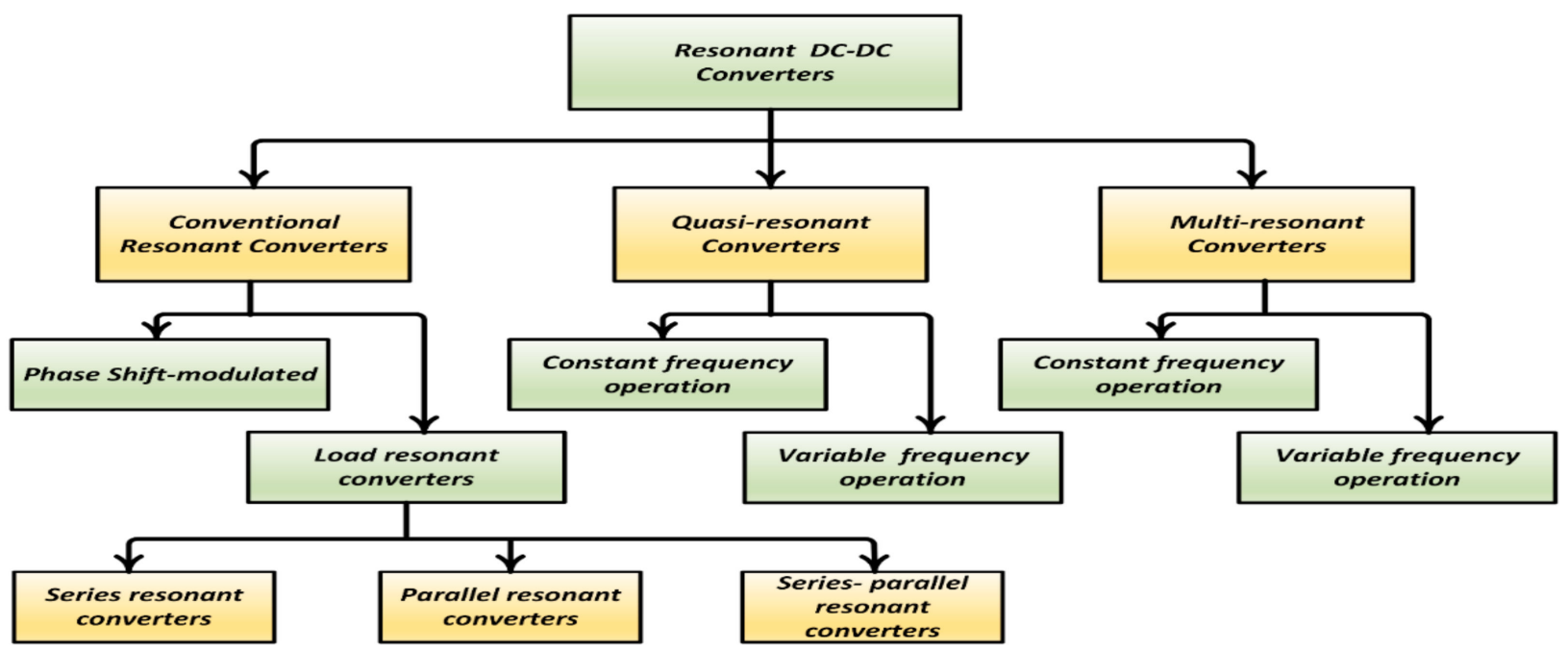

Figure 23. Classification of resonant $D C-D C$ converter [79].

\subsubsection{Series Resonant Converters}

Load resonant converters ( $L R C s$ ) have several distinct characteristics over conventional power converters. $L R C S$ are particularly appropriate for use in high-voltage applications because they allow operation at high frequency to reduce the equipment size without affecting the power conversion efficiency or further stressing the switches. There are three different combinations of $L R C$; ; these are series resonant converters, series-parallel resonant converters, and parallel resonant converters [79]. The $D C-D C(S R C)$ series resonant converter has been utilized in a wide range of voltage and energy applications [101]. The tank is mounted in series with the load network and the rectifier in a series resonant converter $(S R C)$; hence, the generation of the load and resonant tank voltages is dependent on the low voltage divider. The modification of the value of the resonant tank impedance is reliant on the moving voltage frequency to the tank [85]. The loads in SRCs are connected in series with the resonant tank circuit, as designed by $L r$ and $C r$. Figure 24 shows a half-bridge configuration; when $I L r$ is in the positive mode and $T_{1}$ is active, the current of the resonant inductor flows via $T_{1}$, else, it will flow via the $D 2$ diode. On the other hand, when ILr is in the negative mode and $T_{2}$ is active, the current will flow through $T_{2}$, else, it will flow through the $D 1$ diode. Both active switches work in a complementary mode in steady-state symmetrical service. The converter has several potential working modes based on the ratio of the switching frequency Fs to the converter resonant frequency $\mathrm{Fr}$ [102-104]. 


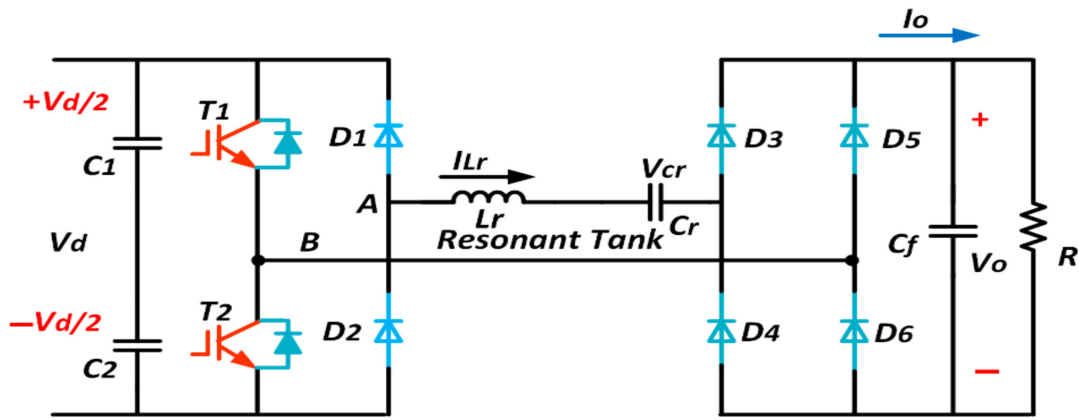

Figure 24. SRC half-bridge configuration [103].

The impedance value of the resonant tank, as shown in Figure 25, varies as a function of the driving voltage frequency to the tank. However, the impedance of the resonant tank can be modified through adjustment of the moving voltage frequency to the resonant network (see Figure 25); the proper resistive value to the RTN, as provided by the rectifier, can be estimated using Equation (15), while the input voltage is fed to the tank impedance and the effective resistance [104]. It is expected that the voltage gain of the SRC should be $<1$ as the configuration framework of the SRC circuit can be estimated using Equation (16). In a light load scenario where the value of the load resistance is higher than the impedance of the resonant network $Z_{O}$, all the input voltages will be fed to the load; hence, it will be hard to regulate the production at light load [87,105].

$$
\begin{gathered}
R_{a c}=\frac{8}{\pi^{2}} R_{L} \text { Reflected load resistance } \\
M=\frac{V_{o}}{V_{i n}}=\frac{1}{\sqrt{1+Q^{2}(1 / F-F)^{2}}} \text { Voltage gain }
\end{gathered}
$$

where $Q$ is the quality load factor, which can be calculated using the relation:

$$
Q=\frac{Z_{O}}{R_{a c}}
$$

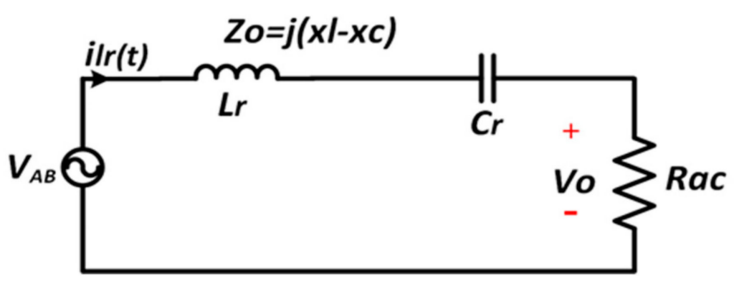

Figure 25. Equivalent circuit of the DC-DC series resonant converter [16].

As mentioned above, there are several potential working modes of the SRC converter, which are conductive mode, frequency switching, and ranges of soft switching. These modes and their limit have been investigated in previous studies [106,107]. The SRC modes can also be classified under discontinuous conduction (DCM) and continuous conduction $(C C M)$ modes based on the ratio of the switching frequency, $F s$, to the converter resonant frequency, Fr.

\subsubsection{Parallel Resonant Converters}

The parallel resonant converter is classified as a two-element tank converter, as shown in Figure 19b. The resonant capacitor $\mathrm{Cr}$ must be in parallel with the load and the diode rectifier network $D R$. In the case of effective load resistance $R_{a c}$, the value is obviously larger compared to resonant capacitor reactance $C r$, meaning that the resonant current is independent from the load. Furthermore, the voltage across the parallel resistance $R_{a c}$ and 
the resonant capacitor can be increased by reducing the load. Due to its voltage filtering, the $R T N$ delivers a sinusoidal voltage $V_{R}$ and the $D R-L P F$ set must be of an inductive nature. The equivalent resistance $R_{a c}$ seen from the input terminals of the DR-LPF set is given by Equation (18), the load quality factor by Equation (19), and $P R C$ voltage gain is given by Equation (20). PRCs can step the output voltage down or up depending on the variation in the control switching system frequency. The voltage output can be adjusted with load states, whereas the resonant current is restricted to resonant inductor data; this causes the PRC to be appropriate for open and short circuit applications [80]. AC-equivalent circuits are shown in Figure 26.

$$
\begin{gathered}
R_{a c}=\frac{\pi^{2}}{8} R_{L} \text { Reflected load resistance } \\
Q=\frac{R_{a c}}{Z_{O}} \text { The load quality factor } \\
M=\frac{V_{o}}{V_{i n}}=\frac{1}{\sqrt{\left[1-\left(\frac{f_{s}}{f_{r}}\right)^{2}\right]^{2}+\left[\frac{f_{s}}{f_{r}} \times\left(\frac{1}{Q}\right)\right]^{2}}} \text { Voltage gain }
\end{gathered}
$$

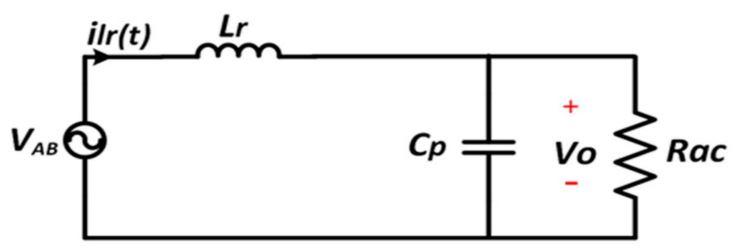

Figure 26. Equivalent circuit of the DC-DC parallel resonant converter [80].

\subsubsection{Series-Parallel Resonant Converters}

Series-parallel resonant converters (SPRCS) combine the advantages of the SRC and $P R C$. The SPRC has an additional capacitor or inductor linked in the resonant tank circuit [23]. Figure 20a shows an LCC-type SPRC, in which an additional capacitor is placed in series with the resonant inductor. LCC offers both load-independent output voltage and output current. This topology is dominated by parallel resonant frequency, and subsequently it presents the same shortcomings as the PRC. LCC cannot operate safely with an open circuit or a short circuit. Figure $20 \mathrm{~b}$ indicates an LLC-type SPRC, in which an additional inductor is connected in parallel with the resonant capacitor in the SRC. LLC has the ability to achieve no load regulation that was not possible in the SRC by employing an inductor in parallel to the resonant capacitor. Through such modification, the LLC topology allows the regulation of the output voltage from zero to maximum under any load condition with relatively small switching frequency variation. LLC also has some restrictions, for instance, startup and short-circuit protection are difficult to achieve due to a flat gain above the series resonant frequency $f_{r s}$. Then, as with $L C C$, the $L L C$ topology cannot operate safely with an open circuit at frequencies close to $f_{r S}$ and cannot operate safely with a short circuit at frequencies close to parallel frequency $f_{r p}[80,108]$. However, there are many possible combinations of the resonant tank circuit. Detailed analysis can be found in [109]. In this context, the type of LLC was discussed as one of the types of this technology, as shown in the equivalent circuit in Figure 27. The LLC equivalent circuit of Figure 27 has a capacitor $C_{r}$ connected in series with the inductor $L_{r}$, and the load is connected in parallel to the inductor $L_{p}$. VAB is the fundamental component of a square waveform Vin that drives the switches of the CSN. The inductor $L_{p}$ can be replaced by the magnetizing inductance if a transformer is used in the circuit. The topology has two resonant frequencies: the series resonant frequency $f_{r s}$ due to the resonant element $L s C s$ 
and given by Equation (21), and the parallel resonant frequency $f_{r p}$ due to all the $R T N$ elements and given by Equation (22). Note that $f_{r s}>f_{r p}$ and $f_{r p}=0$.

$$
\begin{gathered}
f_{r s}=\frac{1}{2 \pi \sqrt{L_{r} C_{r}}} \\
f_{r p}=\frac{1}{2 \pi \sqrt{\left(L_{r}+L_{p}\right) C_{r}}}
\end{gathered}
$$

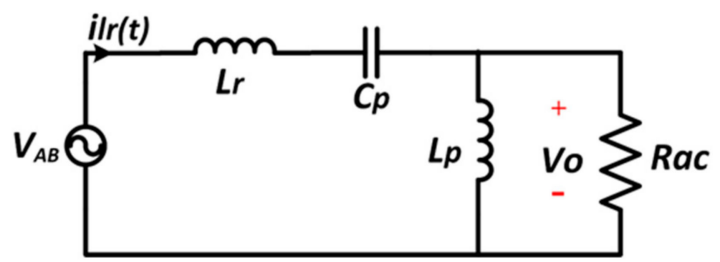

Figure 27. Equivalent circuit of the DC-DC series-parallel resonant converter [80].

\section{Multilevel Inverters (MLIs)}

In recent years, a growing number of industrial applications have necessitated the use of higher-power equipment. Medium-voltage and megawatt power level converters are needed in some medium-voltage motor drives and utility applications. It is difficult to link only one power semiconductor switch directly to a medium-voltage grid; as a result, in high-power and medium-voltage conditions, a multilevel power converter structure has been implemented as an alternative [23]. There are many MLC topologies in existence; thus, in this study, only the most common multilevel converters have been assessed. The pros and cons of these multilevel inverter topologies are discussed in detail in this section. Besides being employed as high-power converters, multilevel converters are extensively utilized in renewable energy sources (wind, fuel cells, etc.) by associating the $P V$ modules on one side and high-power loads on the other side [25]. Multilevel converters began as a three-level inverter introduced by [110]. The main difference between the two-level source voltage inverter (VSI) and the MLC is in the levels of the voltages; for the two-level VSI, they normally generate only two levels of voltages, while an infinite number of voltage levels can be generated by the MLI. The MLI has at least three voltage levels; the output of a power converter is determined based on the consistency of its current and voltage waveforms [111]. The multilevel inverter concept $(M L I)$ for generating $A C$ signal does not only rely on two voltage levels, as shown in Figure 28. Alternatively, a variant of the reinforced smooth wave is applied to most voltage levels to the other, with a small $d v / d t$ and less harmonic distortion. This produces a smoother waveform with more inverter voltage levels, but with many design rates, it becomes more complicated, involves more parts, and needs a more complex inverter controller [112]. Multilevel converters are more often considered due to their high voltage operation ability, great efficiency, small losses from switching, operation at both fundamental and high switching frequency of pulse width modulation (PWM), and low output of EMI [113]; therefore, the system as a whole will be more costly. On the contrary, the emphasis is to raise the circuit complexity via a reduction in the number of switches and gate driver circuits [113,114]. Figures 28 and 29 show two, three, five, and seven levels, respectively. 


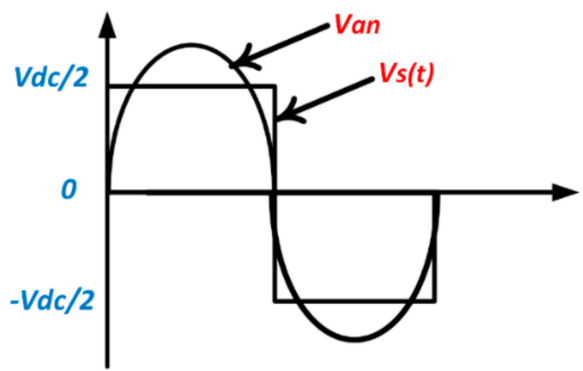

Figure 28. Two-level waveform without PWM [112].

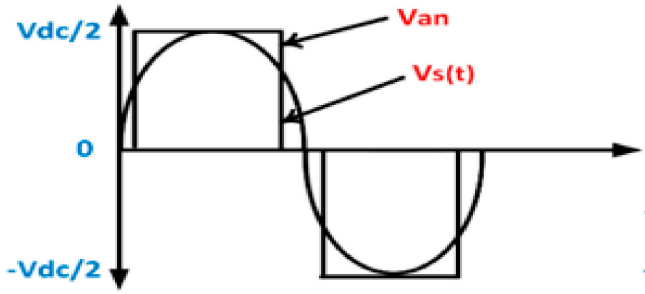

(a)

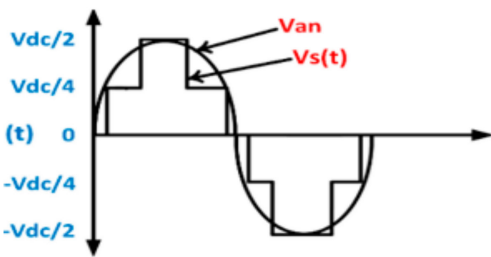

(b)

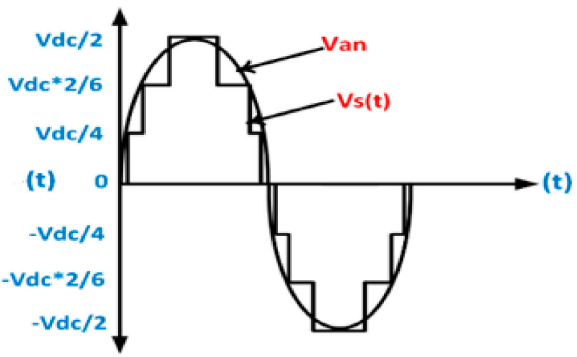

(c)

Figure 29. (a) Three-, (b) five-, and (c) seven-level (multilevel) waveforms [112].

\subsection{Comparison between Conventional and Multilevel Inverter}

Table 2 below lists the differences between traditional and multilevel inverters. It should be noted that, in this context, the term "conventional converter" refers to a converter with fewer than three levels.

Table 2. Comparison between multilevel and traditional converters.

\begin{tabular}{|c|c|c|}
\hline Item & Conventional Inverter & Multilevel Inverter \\
\hline Harmonic & $\begin{array}{c}\text { The output has high } \\
\text { harmonics }\end{array}$ & $\begin{array}{c}\text { The output has low } \\
\text { harmonics. }\end{array}$ \\
\hline Voltage & $\begin{array}{l}\text { It is not allowed for use in } \\
\text { high-voltage applications. }\end{array}$ & $\begin{array}{c}\text { It can be used in high-voltage } \\
\text { applications. }\end{array}$ \\
\hline Level of voltage & $\begin{array}{l}\text { It is not possible to generate } \\
\text { high voltage levels. }\end{array}$ & $\begin{array}{c}\text { It is possible to generate high } \\
\text { voltage levels. }\end{array}$ \\
\hline Stresses & $\begin{array}{l}\text { The voltage stresses on } \\
\text { switching are greater. }\end{array}$ & $\begin{array}{c}\text { The voltage stresses on } \\
\text { switching are less. }\end{array}$ \\
\hline Losses of switching & Increasing switching losses. & Decreasing switching losses. \\
\hline Switching frequency & Switching frequency is high. & Switching frequency is low. \\
\hline Rate of change & $\begin{array}{c}\text { The rate of voltage change } \\
\text { is high. }\end{array}$ & $\begin{array}{c}\text { The rate of voltage change } \\
\text { is low. }\end{array}$ \\
\hline
\end{tabular}

\subsection{Classification of Multilevel Inverters}

MLIs are important for medium and high voltage usage due to their capability of synthesizing a sinusoidal voltage at different DC levels [115]. Although there are many 
$M L I$ topologies, they are generally classified into neutral-point-clamped (diode-clamped), cascaded, and flying capacitor (capacitor-clamped) types, as shown in Figure 30 [116-119].

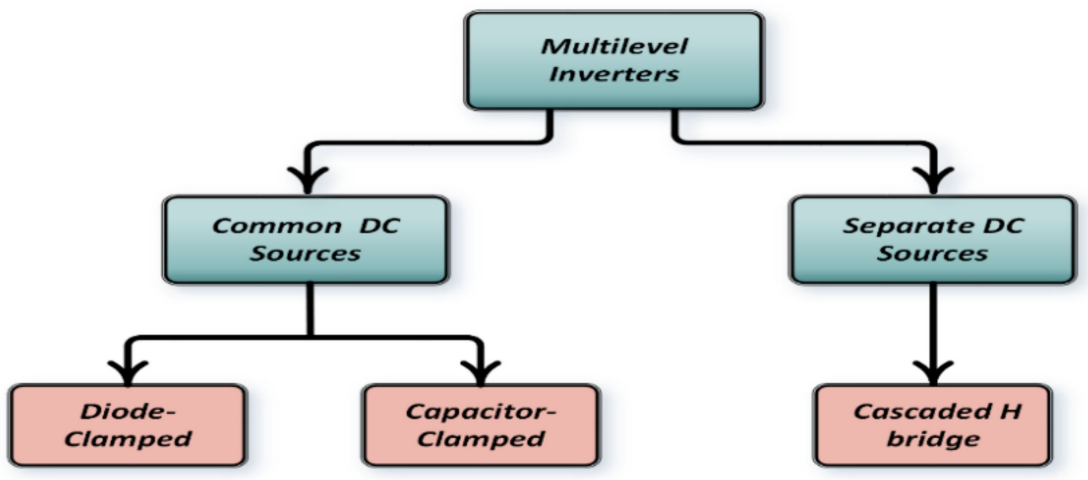

Figure 30. Classification of multilevel inverters [119].

\subsubsection{Diode-Clamped Multilevel Inverter}

The neutral-point-clamped (NPC) PWM topology is the first practical generation of MLI (Figure 31); this multilevel inverter is clamped by a diode using clamping diodes. It helps to reduce the electronic devices' voltage tension. It was considered the first-generation MLC, called the three-level NPC, and was first introduced in 1981 by Nabae et al. [110,111]. Nonetheless, this topology suffers technical problems if used as high-power converters. It needs diodes with high-speed clamping that are subject to the stress of reverse recovery. Due to the series connection of the diodes, the design complexity is a key concern. Half of the input $D C$ voltage is the maximum output voltage. This problem is simply eliminated by increasing the number of components, such as switches and diodes [113,120-122]. This topology, like other techniques, possesses advantages and drawbacks; one of the benefits is that the control technique is basic, and it utilizes back-to-back inverters. Another positive point is that the switch voltage is just half the $D C$-link voltage. An additional benefit is that material declines when the number of levels rises along with the distortion. Furthermore, at the fundamental frequency, the efficiency is great, aside from capacitor capacity being small and preloaded. Despite these positive effects, the diode-clamped multilevel inverter has some weak points, such as the need for more clamping diodes when the number of levels increases, and when control and monitoring are not correct, a considerably large amount of $D C$ will be discharged $[113,120]$.

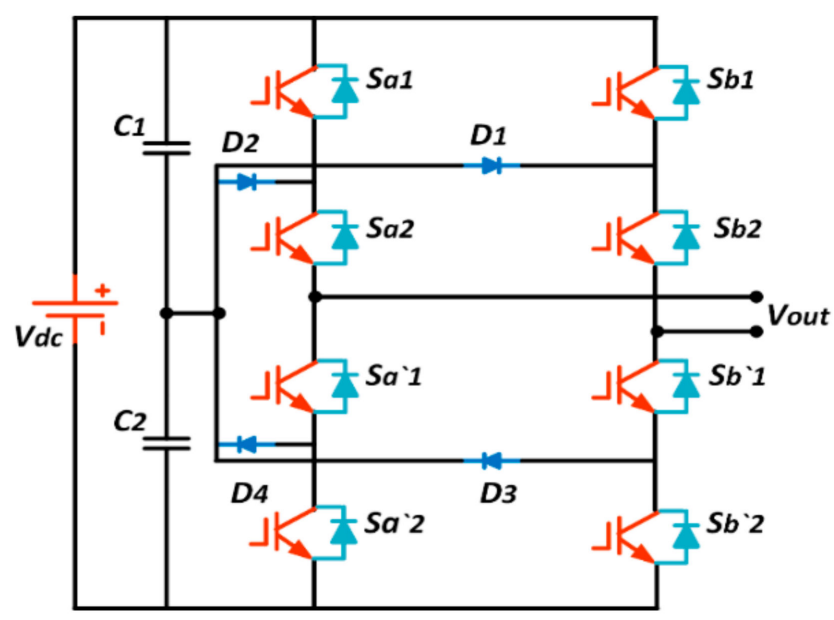

Figure 31. Diode-clamped multilevel inverter [23]. 


\subsubsection{Capacitor-Clamped (Flying Capacitor)}

This is another type of multilevel inverter [123,124]; it is like the diode-clamped inverter as in $[125,126]$ and uses capacitors to clamp the voltage of the unit instead of diodes [123]. The flying capacitor (FLC) converter was introduced in the 1990s by [124,127] as another modification of the multilevel inverter topology. Its fabrication involved the serial connection of capacitors' clamped switching cell, thereby allowing the transfer of limited voltages to the electrical devices through the capacitors. It differs from the diodeclamped MLI by having capacitors and not diodes; the work of the capacitors is to separate the $D C$ supply voltages. However, $V D C$ represents the voltage across each switch and capacitor. An inverter of $m$ level flying cap needs $\left(2^{m-2}\right)$ switches, with $\left({ }^{m-1}\right)$ number of capacitors [113].

The $D C$ side of this topology has a ladder structure capacitor, and the voltage passing through each neighboring capacitive branch differs. This voltage difference is considered to determine the size of the output voltage phase, which is equivalent to VDC. In contrast to the diode-clamped multilevel converter, the major benefit of the flying capacitor inverter is that it has redundancies for internal voltage levels. In other words, to obtain a similar output voltage, there is a need to combine two or more different valid switches. Furthermore, the flying capacitor topology has phase redundancy, while only a line redundancy is observed in the diode-clamped inverters. This is an important feature because it is the basis for using capacitive branch voltage balancing control techniques. The output voltage level determines the number of redundant states; in this kind of $M L C$, a balance in the voltage of the capacitors must be maintained. This can be achieved by using the appropriate sequences of regulation so that the internal capacitors recharge and discharge evenly over time. Nonetheless, there are some risks, as follows [25,128]:

- Voltage level control is difficult for all capacitors; it is also a complex task to pre-charge all the condensers at the same voltage level.

- The efficiency of switching is low.

- In a diode-clamped $M L I$, several capacitors are used, and these are mostly expensive and bulkier compared to the clamping diodes. A flying capacitor multilevel topology is shown below in Figure 32.

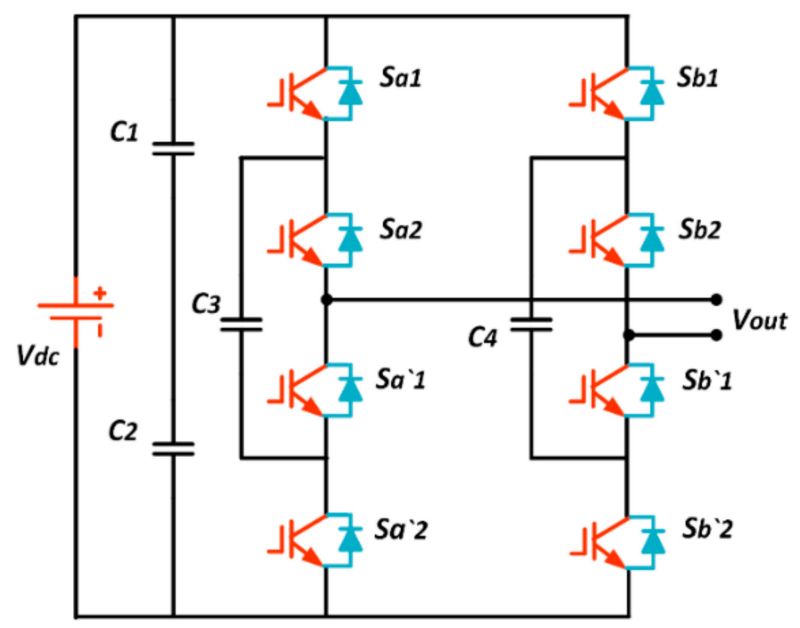

Figure 32. Flying capacitor multilevel inverter [23].

\subsubsection{Cascaded H-Bridge}

Baker and Bannister [129] patented the first converter topology in the mid-1970s, which was capable of producing multilevel voltages through the source of specific $D C$ voltage. A cascaded $H$-bridge converter was suggested by [130] for the elimination of the drawbacks of FLC and NPC topologies, such as the additional clamping diodes and capacitors. The cascaded $H$-bridge $M L I$ requires fewer parts per switching stage when compared to diode-clamped and flying capacitor inverters. The group of switches and 
condensers in a cascade $H$-bridge $M L C$ is termed as $H$-bridge, comprising isolated $D C$ voltage sources $[120,131]$. This topology utilizes more than one $D C$ source in the $H$-bridge inverter. Each converter achieves output at various levels, as shown in Figure 33 [114], due to the connection of different power conversion cells. The $H$-bridge is made up of a pair of switches and condensers. For each $H$-bridge, a separate input $D C$ voltage is achieved as it generates a sinusoidal voltage output. Series of attached $H$-bridge cells are used in the inverter, with each having three different levels of $D C$ voltage, which are zero, negative $D C$ voltage, and positive $D C$ voltage. Each $H$-bridge cell has its average voltage output as the sum of all the produced voltages.

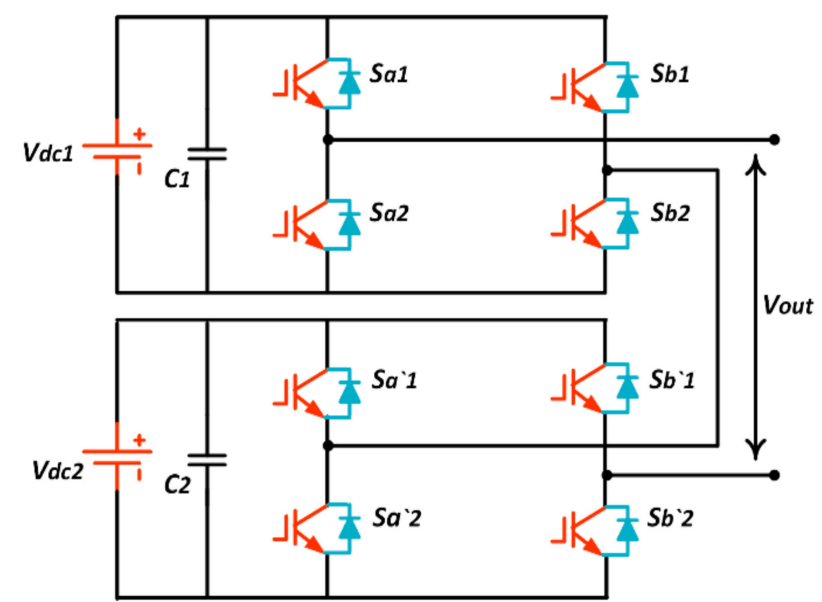

Figure 33. Cascaded multilevel inverters [23].

If the number of cells is $m$, the number of output voltage levels will be $\left(2^{m+1}\right)$. Figure 33 depicts the structure of a five-level $H$-bridge inverter [113]. The study by Lai and Peng (1997) focused on the peculiarities of the NPC and FLC topologies; the study was later patented in 1997. Cascaded H-bridge MLCs (CHBMLCs) have since attracted great interest in several applications due to their attractive characteristics, such as:

- $\quad$ Ease of packing and storing.

- Producing voltage in common mode, reducing stress.

- Small distortions in the input current.

- Functioning at both simple switching frequencies.

- The THD of the output waveform being very small without any filter circuit.

However, the inverter has drawbacks, such as:

- $\quad$ Each module needs different $D C$ sources or capacitors.

- The large quantity of capacitors requires a more complex controller.

\subsection{Comparison of Multilevel Inverters}

Table 3 below presents the comparison of multilevel converters in terms of:

- The number of devices for semiconductors in each body;

- Harmonic component amplitude;

- The number of capacitors in each leg phase;

- The available number of $D C$ bus capacitors;

- Full harmonic output voltage distortion;

- Complexity management based on power switches and unbalances in voltage, and;

- Cost calculation related to the power circuit. 
Table 3. Comparison of multilevel inverters based on the number of components utilized.

\begin{tabular}{|c|c|c|c|c|}
\hline No & Topology & Diode Clamped & Flying Capacitor & Cascaded HB \\
\hline 1 & Semiconductor power switches & $2 \times(m-1)$ & $2 \times(m-1)$ & $2 \times(m-1)$ \\
\hline 2 & DC bus capacitors & $(m-1)$ & $(m-1)$ & $\frac{(m-1)}{2}$ \\
\hline 3 & Balancing capacitor per phase & 0 & $\frac{(m-1)(m-2)}{2}$ & 0 \\
\hline 4 & Clamping diodes per phase & $(m-1)(m-2)$ & 0 & 0 \\
\hline 5 & Unbalancing voltage & Average & Great & Tiny \\
\hline 6 & Application & $\begin{array}{l}\text { Renewable energy, motor } \\
\text { drive system, static } \\
\text { synchronous } \\
\text { compensator } \\
\text { (STATCOM), HVDC/AC } \\
\text { transmission lines. }\end{array}$ & $\begin{array}{l}\text { Renewable energy, motor } \\
\text { drive system, static } \\
\text { synchronous } \\
\text { compensator } \\
\text { (STATCOM). }\end{array}$ & $\begin{array}{l}\text { Renewable energy } \\
\text { battery system, motor } \\
\text { drive system, power } \\
\text { factor compensators, } \\
\text { electric vehicle drives. }\end{array}$ \\
\hline
\end{tabular}

\section{Structural Hybrid of Reviewed Converters}

There are several hybrid topologies reported in the literature. The aim of developing hybrid topologies is to ensure the achievement of an efficient system that combines the features of both converters. This section reviews the combination of each two of the three converters highlighted in the previous sections. The hybrid structures discussed here are: multilevel bidirectional, multilevel resonant, and bidirectional resonant converters. The applications of these hybrid converters, especially for energy storage and grid integration, are discussed in the next section.

\subsection{Bidirectional Resonant Converters}

These converters are normally used as a linkage between the energy storage components and the grid utilities or $D C$ bus [132]; they can also be used in $E V s$, microgrids, and vehicle-to-grid $(V 2 G)$. BDCs are normally connected with energy storage components such as supercapacitors or batteries, with a wide range of voltage variation during operation. Hence, $B D C$ s are not considered efficient over a wide range of voltages $[133,134]$. More attention has been given to the dual active bridge $(D A B)$ converter because of its simple nature, high efficiency, safety, and wide range of soft-switching capability [135]. $B D C$ s can also be achieved with a current-fed inverter on the transformer side with low voltage and with a voltage-fed inverter on the side of the transformer with high voltage. However, conventional converters are associated with certain issues, such as switching losses and not being able to achieve soft switching under wide load changes. Hence, the proposed resonant-based bidirectional $D C-D C$ converter was suggested to address these issues of conventional converters $[136,137]$. Various studies have focused on the alteration of resonant network structures to improve the performance of resonant-type IBDCs. Most of the studies have concentrated on CLLC- and CLLLC-type resonant IBDCs because of their symmetrical attributes in both power flow directions. The study by [134] proposed bidirectional designs of $C L L C$ and $C L L L C$ resonant converters that will ensure high-efficiency operation over a wide gain range. The attributes of $L L C$ resonant converters include low cost, high power, and better efficiency, and these made it suitable for industrial application [138]. The most popular bidirectional isolated converters in the industries are series resonant converters (SRCS) because they can realize open-loop bidirectional power flow operation. $L L C$ resonant tanks are considered better options for improving the regulation of output voltage under bidirectional operation because their usage in bidirectional converters demands two different modes of operation based on the power flow direction [139]. The study by [140] presented a light electric vehicle fast charger with a lithium-ion battery and supercapacitor, together with an $A C / D C$ rectifier, full-bridge $L L C$ resonant converter, as shown in Figure 34, and light electric vehicle ( $L E V)$ battery. The research suggested a fastcharging system using a soft-switched $L L C$ resonant converter in the ZVS area. Compared to the past, the regular use of lead-acid batteries has been reduced due to emissions into 
the air and environment; therefore, new $L E V$ systems with fast charging mechanisms have been proposed by using a lithium-ion battery of 800 Watt-hour and a supercapacitor of $50 \mathrm{Wh}$.

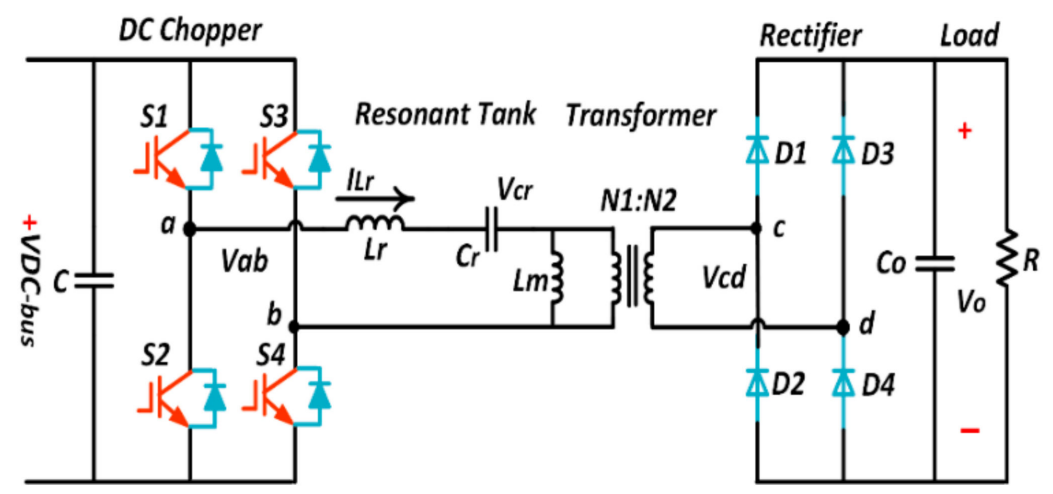

Figure 34. Circuit diagram of full-bridge LLC resonant converter [140].

\subsection{Multilevel Bidirectional DC-DC Converter}

Due to the ability of multilevel converters to reduce power losses, the voltage stress of switches, and the total harmonic distortion (THD) of output signals [141], they have been widely developed and tested in various applications to achieve beneficial points, such as good efficiency and low and optimal cost. The study by [142] presented a new multilevel boost-buck $D C$ - $D C$ converter that can be used when similar grounding is needed at both sides of the converter. The topology is comprised of a back-to-back connection of $2 n$ diode-clamped or level active converter legs. The efficiency of this structure for the $M L C$ is higher at a higher number of levels.

The study presented by Shukla focused on the elimination of the imbalance in $D C$ capacitor voltage, which has been the major problem of diode-clamped MLIs with $>3$ levels. The study proposed the connection of the voltage-balancing circuit based on the buck-boost chopper to the DC-link of diode-clamped MLIs; this was considered effective in addressing the issues of line faults, disturbances, and transients, even though the cost and system complexity are increased by adding such a circuit to the system [143]. Considering that the HBMLC topology demands the use of separate voltage sources, it is suitable for EVs and plug-in hybrid $E V S$ as these systems are dependent on a high number of batteries. The other interesting feature of the $M L I$ is that operations can proceed in a bidirectional mode, which allows the charging and discharging of the batteries [141,144]. The neutral point diode-clamped (NPC) dual active bridge (DAB) converter was designed in [145], and the study applied a capacitor voltage balancing method in order to facilitate voltage balancing. The two NPC legs, as shown in Figure 35, can generate five-level voltages across the primary winding of the medium frequency transformer. The balancing methods are dependent on the direction of power flow through the $D A B$ converter, but in this research the authors suggested a voltage balancing controller that is independent of power flow direction and does not require adjustments of active voltage vectors via the modulator. They concluded that the proposed voltage balancing approach is very and globally effective under all operating conditions of the converter [145]. 


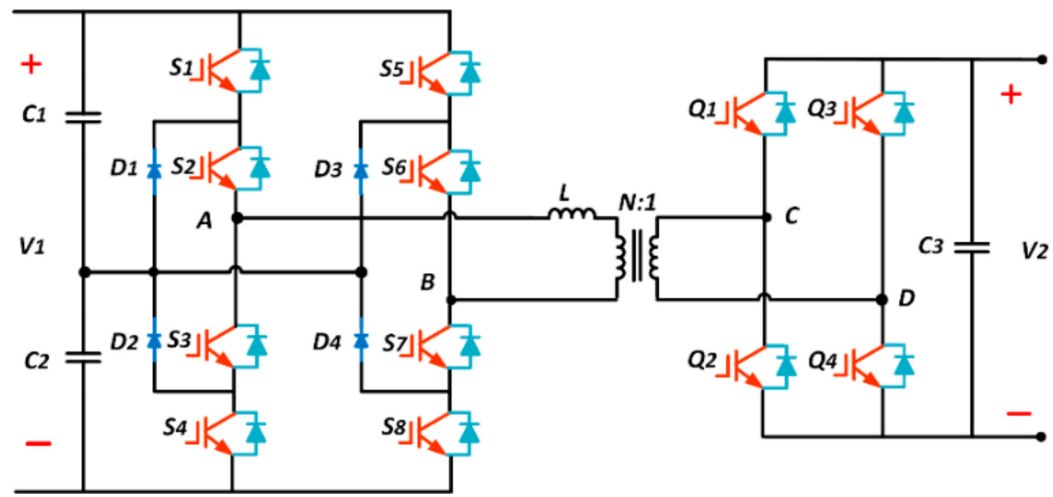

Figure 35. Circuit diagram of five-level NPC DAB converter [145].

\subsection{Multilevel Resonant Converters}

To meet the demands for high-voltage operation, more novel structures are needed in high-power applications to achieve better performances. This multilevel structure can reduce the voltage stress of power devices and this made them a good alternative [146]. In $D C-D C$ conversion, resonant converters are potential alternatives owing to their softswitching attributes in a range of operations. In such situations, $L L C$ resonant converters are better options due to their advantages, such as ZCS for rectifier diodes and ZVS for power switches. Another multi-phase multilevel LLC modular resonant converter that can realize ZCS for rectifier diodes and ZVS for primary switches, and can decrease voltage stress to one-nth of the input voltage under a range of load and input voltages, has been proposed to meet the demands for high-power and high-voltage operation. The system was also proposed to improve the power processing ability of the LLC resonant converters in multilevel operations [147]. With this approach, the voltage stress on the power devices will be reduced, making it suitable for use in low-voltage rated MOSFETs. With low-voltage rated MOSFETs, conduction losses will be reduced for a given area and the switching losses due to ZVS will remain low [147]. Achieving ZVS in multilevel operation also requires a reduction in the dead-time and magnetizing inductance current due to the storage of lower energy in the parasitic capacitances of the MOSFETs, thereby increasing the converter efficiency. The study by [148] presented a new two-phase interleaved flying capacitor $L L C$ resonant converter in which multilevel operation and multi-phase operation are combined. The need for the flying capacitor is to reduce the voltage stress on the primary side of the MOSFETs to ensure a balance in the currents generated by the two phases, as well as to improve the power processing capabilities of the system. Hence, the converter exhibited all the positive attributes of conventional LLC converters but retained the low sensitivity attribute to mismatches in the resonant tank parameters without requiring extra components. This made the system suitable for high-output current applications. A multilevel flying capacitor-based single-stage AC-DC LLC topology has been proposed to address the dilemma of the voltage balancing of $D C$-bus capacitors and to lessen the voltage stress of the switching devices. The suggested three-level inverter configuration ensures zero voltage switching (ZVS) for all the switches, lower circulating currents, less switching stress, and lower losses. For improved efficiency, the converter employs a bridgeless rectification approach, and the power factor is practically unity by operating the source-side inductor in discontinuous current conduction mode. The output voltage of the converter is regulated using variable switching frequency control, while the DCbus voltage is regulated via pulse width modulation. This control technique works well to maintain almost constant $D C$-bus voltage throughout a wide range of line and load variations. Figure 36 shows the three-level flying capacitor LLC resonant converter [149]. The study by [150] presented a five-level cascaded LLC resonant converter; the design and analysis of the system were presented for use in energy storage systems (ESSs) or grid-connected applications. The proposed converter operates in the same manner as a step-down converter; it also achieves ZCS. 


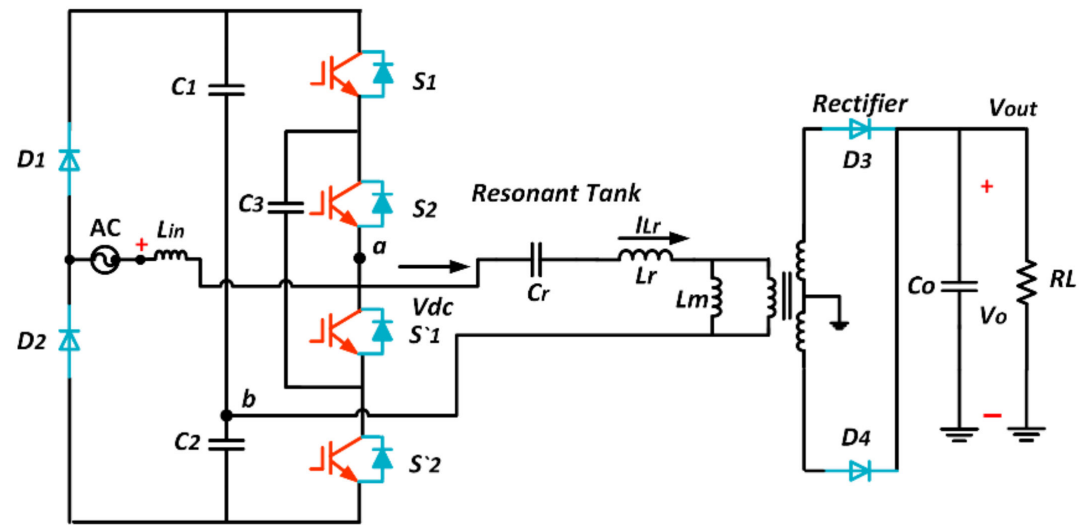

Figure 36. Circuit diagram of three-level single-stage LLC converter [149].

\subsection{Multilevel Bidirectional Resonant Converters}

The unique characteristics of multilevel inverters make them attractive to a variety of medium to high-power, high-voltage applications. Multilevel inverters have several benefits, such as reduced voltage stress, reduced loss of individual semiconductor chips, improved power efficiency, and reduced electromagnetic interference. The most significant challenges in multilevel inverters are voltage balancing, the increased number of semiconductors and capacitors, and more complicated control. The best structure can be chosen from a variety of classic and advanced multilevel inverter configurations. The most appropriate option is determined by the application, load, and requirement [151]. Although many papers have investigated different topologies, modulations, and control techniques of multilevel inverters with bidirectional or resonant converters, only a few studies have introduced the combination of these three converters; this section briefly reviews the existing literature on these structures. The study by [152] introduced the bidirectional multilevel resonant switched capacitor converter; this work presented a method that significantly improves the proposed converter's efficiency through topology modification. In a multilevel topology, the converter can achieve a high voltage ratio, which reduces voltage stress on switches and allows for high-power performance. The converter can be used as a link between $D C$ voltage systems that are used in several applications. Furthermore, the primary objective of the research was to verify the achieved topology improvement using silicon carbide $(\mathrm{SiC})$ and silicon $(\mathrm{Si})$ switches in a four-level bidirectional resonant switched capacitor with a $0.5 / 2 \mathrm{kV}$ voltage conversion ratio. The proposed converter was composed of a basic switched-capacitor (SC) structure that makes energy transfer in both directions possible. The study concluded that the voltage gain was more stable, and the method was efficient with Si MOSFET; also, the system showed a negligible decrease in efficiency versus power with increases in power. A bidirectional modular multilevel resonant $(B M M R) D C-D C$ converter has been proposed for medium linkage with low-voltage grids; the desirable features of $B M M R$ converters include:

- Bidirectional power conversion ability.

- Modular structure with manufacturable, standardized submodules, and fault-tolerant operation that is simple to achieve.

Owing to these characteristics, the $B M M R$ converter is a strong contender for $D C$ distribution applications. The authors presented an analysis of the converter's operation principles and submodule voltage balancing in a steady state. The proposed topology and control methods were checked using a $500-\mathrm{kW}$ simulation model and experiments on a down-scaled prototype, where the employed structure was a half-bridge modular multilevel structure on the medium voltage $(M V)$ part and a full-bridge structure applied on the low voltage $(L V)$ side [153].

Bidirectional three-level DC-DC converter soft-switching was presented by [154], which, when combined with a simple auxiliary circuit, can effectively minimize switching power losses. To reduce the turn-on switching power losses of main power switches, the 
researchers utilized double $L C$ resonant circuits. In comparison to previous converters that work without any auxiliary circuits and suffer from high switching losses, the proposed converter reduces switching power losses and improves power performance. The proposed converter outperformed conventional converters in terms of power efficiency. For the rated load state, it achieved power efficiencies of $97.7 \%$ in the step-up mode and $97.8 \%$ in the step-down mode.

The study made the following conclusions:

- The proposed converter can be used in a grid-connected battery energy storage device that needs high power density and performance. High-performance inverters, such as neutral-point-clamped and three-level inverters, can be interfaced with the proposed converter due to their three-level power conversion structure.

- The proposed converter can be used for both single-phase and three-phase gridconnected applications as a bidirectional $D C-D C$ converter.

- The proposed converter is intended to be a good fit for the interface between the battery and the grid-connected inverter, allowing for high-efficiency electrical power exchange and energy conversion management.

An isolated multilevel $D C / D C$ converter for a power cell in a solid-state transformer (SST) that converts medium-voltage $(M V)$ AC input to low-voltage $(L V)$ or medium-voltage DC output has been studied. The $A C / D C$ stage uses the three-level diode neutral-pointclamped $(D N P C)$ types to take a higher voltage at $A C$ input terminals. The high frequency and high efficiency design needs to be met with soft switching in the whole operating range. To achieve this aim, the $L L C$ resonant topology is utilized in this configuration for isolated power conversion, owing to its high efficiency and high power density. The (DNPC) is first considered as the primary side topology for an $L L C$ resonant circuit since it is the same structure as the phase legs for the $A C / D C$ stage. The $L L C$ circuit with a three-level DNPC as the primary side and two-level full bridge as the secondary side is shown in Figure 37. The transformer in the $D C / D C$ stage needs to provide medium voltage isolation at a high power rating [155].

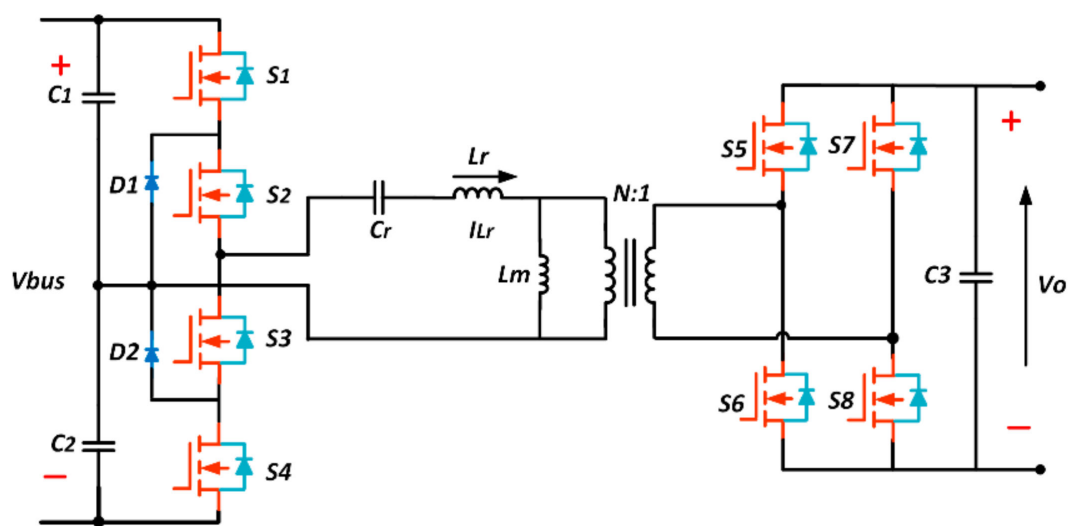

Figure 37. Circuit diagram of three-level natural diode-clamped bidirectional LLC resonant converter [155].

\section{Applications}

Reducing the impact of greenhouse gases (GHGs) by reducing CO2 (carbon dioxide) and other emissions is one of the most daunting dilemmas that people are currently facing. As electricity generation is one of the key reasons for emissions, it is important to find alternative methods for producing clean electricity. In this regard, renewable energy resources, such as wind and solar energy, are among the most significant replacements for conventional fuel-based energy production. Nevertheless, when these tools are employed alone, the intermittent existence of most renewable sources does not permit a consistent and continuous source of energy. The fluctuations in the generated energy from these sources could hamper the power quality of the associated grid. To overcome such fluctuations, 
energy storage systems should be used to generate smooth power while maximizing the energy output of the RES. This also minimizes the needed contribution from conventional power systems, thereby keeping CO2 emissions low. The utility grid needs to be technologically advanced in terms of grid stabilization, power quality, frequency and voltage subsidization, load shifting, system reliability improvement, and smoothing the energy output of renewable resources. In addition, restructured power markets offer chances to leverage energy arbitration markets and generate revenue by purchasing off-peak low-cost electricity and selling high-cost peak electricity [156]. Table 4 shows some applications of different converters.

Table 4. Applications of different converter types.

\begin{tabular}{l}
\hline Converter Type \\
\hline \\
Bidirectional DC-DC \\
Converter Buck Boost, \\
Full-Bridge, Multi-phase \\
Interleaved and Floating \\
Interleaved Bidirectional.
\end{tabular}

Boost Bidirectional DC-DC Converter.

PV applications
Microgrid energy storage application

\section{Application Area}

Description

A bidirectional $D C-D C$ converter topology relevant to microgrid energy storage, including non-isolated, isolated, and interleaved topologies, has been addressed. While it is critical to select an appropriate bidirectional converter topology to provide efficient power transfer between the $D C$ bus and the storage units, it is also critical to select a suitable control approach to ensure the microgrid's resilience, reliability, and stability.

\section{Reference}

The proposed topology for harnessing and storing $P V$ energy is derived by combining a buck-boost converter with a bidirectional boost converter. It also tries to store energy so that it can be used in the event of a power outage. The suggested converter has a higher conversion gain, is simple to use, and the method of control is adjustable by altering the direction of the power flow. The converter is equipped with two unidirectional ports and one bidirectional port; at the bidirectional port, a battery is installed for energy storage via the bidirectional boost converter.

Uninterruptible power supplies (UPS) typically require bidirectional $D C-D C$ converters to interface batteries to a $D C$ bus.
Three-phase Bidirectional $D C-D C$ Converter.

Uninterruptible power supplies (UPS) Three-phase $D C-D C$ converter topologies for higher power and current applications produce less ripple current and less current stress on the devices. Low ripple current is an especially essential attribute since excessive ripple current can shorten the battery life in UPS systems.

The LLC converter is designed for the output voltage range of 15 $\mathrm{V}-20 \mathrm{~V}$ for a lead-acid battery with the input range of $30 \mathrm{~V}$ and
LLC Resonant $D C-D C$ Converter.

Battery charging with an efficiency range of $88-92 \%$. The circuit is simulated by applying PSIM software and the output voltage is regulated with the help of a PI controller as a feedback path.

An $L C$ resonant converter was proposed for grid-connected renewable energy sources; the system uses a step-up resonant converter for grid-connected RES. The converter delivers power
$L C$ Resonant $D C-D C$ Converter.
Grid-connected renewable energy sources (RESs) by charging from the input and discharging at the output via the resonant inductor. The resonant capacitor is used to accomplish zero voltage on/off and zero current switching for active switches and ZCS for rectifier diodes.

An isolated soft-switching current-fed $L C C-T$ resonant $D C-D C$ converter for fuel cell $/ P V$ applications has been presented. This converter is capable of achieving zero current switching for voltage doubler diodes and zero voltage switching for front-end inverter switches. To obtain the rated output voltage of $380 \mathrm{~V}$, a proof-of-concept prototype rated for $288 \mathrm{~W}$ was created and subjected to harsh load and input conditions. 
Table 4. Cont.

\begin{tabular}{|c|c|c|c|}
\hline Converter Type & Application Area & Description & Reference \\
\hline $\begin{array}{l}\text { Five-level Cascaded } \\
\text { Multilevel Inverter. }\end{array}$ & $\begin{array}{l}\text { Renewable energy } \\
(P V \text { and wind } \\
\text { system })\end{array}$ & $\begin{array}{l}\text { A five-level cascaded medium-voltage converter has been } \\
\text { proposed as a high-frequency link multilevel cascaded } \\
\text { medium-voltage converter for direct grid integration of } \\
\text { renewable sources to minimize the voltage imbalance and } \\
\text { common mode issue. A } 1.73-\mathrm{kVA} \text { prototype system was created } \\
\text { with a modular five-level cascaded converter that converts } 210 \mathrm{~V} \\
D C \text { (rectified generating voltage) to three-phase } 1 \mathrm{kV} R M S \text {, } \\
50 \mathrm{~Hz} A C \text {. }\end{array}$ & [163] \\
\hline
\end{tabular}

The suggested seven-level hybrid cascaded $H$-bridge enables the use of a single power supply, with the remaining ' $n-1$ ' sources consisting of capacitors, and is referred to as a hybrid cascaded $H$-bridge multilevel inverter (HCMLI).

Seven-level Hybrid Cascaded $H$-bridge Inverter.

Hybrid electric vehicles $(H E V S)$
Due to the great number of output levels, the HCMLI produces high-quality output power while maintaining a high conversion efficiency and minimal thermal stress due to its fundamental frequency switching method. By substituting a fuel cell for the capacitance source, which is incompatible with high-temperature operation, and making necessary modifications, this topology can be applied in hybrid electric vehicles (HEVs).
A fuel cell-based multilevel inverter is presented. The basic units are connected in series to provide a larger output level and reduce the number of switches. The installation of the $\mathrm{H}$-bridge

Five-, Seven-, and Fifteen-level Cascaded $H$-bridge Inverter. results in both positive and negative levels in the absence of the $F C$ and DC. The suggested multilevel inverter had output voltage levels of five, seven, and fifteen. The FC considered having an output voltage of $48 \mathrm{~V}$ and is boosted to $400 \mathrm{~V}$.

The proposed system is like an LLC resonant converter but differs by the addition of an additional capacitor and inductor to the circuit's secondary side for bidirectional operation. This makes the resonant network symmetric for operation in both reverse and forward directions. Both ZCS and ZVS can reduce losses and support operation at high frequencies; this reduces the size of filter capacitors and magnetic elements, thereby reducing the volume, weight, and size, as well as increasing the power density of the system.

Dual Active Bridge $(D A B)$

CLL-LC Resonant Converter Topology charging/discharging $(E V)$
The forward and reverse output power capability of the CLLC topology has been investigated. It was discovered that the forward and reverse output power ability of the CLLC converter is asymmetrical, which makes it difficult to fully meet the application requirements of an onboard charger $(O B C)$. An $O B C$ is a power conversion device that converts the grid voltage into a voltage suitable for charging lithium-ion batteries in an electric vehicle. Therefore, a CLLC resonant converter with a modified half-bridge and full-bridge structure attained forward 6.6-kW and reverse 3.3-kW power conversion. Both the highest and lowest battery voltages can achieve an output power of AC $3.3 \mathrm{~kW}$. Among them, $330 \mathrm{~V}$ adopts the full-bridge and $480 \mathrm{~V}$ adopts the half-bridge topology. 
Table 4. Cont.

\begin{tabular}{|c|c|c|c|}
\hline Converter Type & Application Area & Description & Reference \\
\hline $\begin{array}{l}\text { Full-Bridge Bidirectional } \\
\text { LLC Resonant Converter. }\end{array}$ & $\begin{array}{l}\text { Light electric } \\
\text { vehicle }(L E V)\end{array}$ & $\begin{array}{l}\text { The research offered a fast charger prototype for an } L E V \\
\text { equipped with an } 800 \mathrm{Wh} \text { lithium-ion battery and a } 50 \mathrm{Wh} \\
\text { supercapacitor. This prototype fast charger is comprised of an } \\
A C / D C \text { rectifier and a } D C / D C \text { stage. The } D C / D C \text { stage } \\
\text { incorporates a full-bridge } L L C \text { resonant converter for soft } \\
\text { switching and stress reduction. Additionally, it is controlled by a } \\
\text { pulse frequency modulation (PFM) and PI controller using a } \\
\text { constant current and constant voltage transformation method. }\end{array}$ & [140] \\
\hline $\begin{array}{l}\text { Five-level Inverter } \\
\text { Full-Bridge Bidirectional } \\
\text { Converter. }\end{array}$ & $\begin{array}{l}\text { On-board } E V \\
\text { battery chargers in } \\
\text { smart grids }\end{array}$ & $\begin{array}{l}\text { The development of a new on-board } E V \text { battery charger }(E V B C) \\
\text { has been proposed based on a bidirectional multilevel topology. } \\
\text { The proposed design evolved from the standard full-bridge } \\
\text { rectifier by connecting four devices to the split } D C \text {-link as the } \\
\text { power factor correction }(P F C) \text { three-level } D C-D C \text { converter. This } \\
\text { design is capable of generating five different voltage levels. An } \\
A C-D C \text { converter is incorporated in the proposed topology as an } \\
\text { interface on the grid side; it also has a } D C \text { - } D C \text { converter for an } \\
\text { interface on the battery side. A split } D C \text {-link was used to interface } \\
\text { the two converters to ensure different levels of voltage in both } \\
\text { converters. The evaluation result allowed for the validation of the } \\
\text { bidirectional operation mode of the new } E V B C \text { on a multilevel } \\
\text { topology. Considering that the aim of controlling the } E V B C \text { is to } \\
\text { integrate } E V \text { s into smart grids, discussions and evaluations are } \\
\text { based on the grid-to-vehicle ( } G 2 V) \text { and vehicle-to-grid }(V 2 G) \\
\text { modes of operation. }\end{array}$ & [168] \\
\hline
\end{tabular}

High voltages are needed in many medical and industrial applications, such as X-ray generation and electron beam welding; these applications also require large power variations. Regarding X-ray applications, the power available to the X-ray tube normally varies significantly $(<1 \mathrm{~kW}-100 \mathrm{~kW})$ based on the

Five-level Cascaded H-bridge LCC Resonant Converter.

X-ray applications employed radiographic technique or the type and thickness of the material. A new LCC multilevel topology has been proposed to solve the problem that distinguished radioscopy from

fluoroscopy. Fluoroscopy requires long-time exposure to low-power radiation, while radioscopy involves short-time exposure to high-power radiation. Regarding the fact that the converter design should consider the maximum power range, the efficiency will be poor when working at low power levels. This problem can be addressed with the proposed new topology.

A non-isolated soft-switching bidirectional $D C / D C$ converter for interfacing energy storage in a DC microgrid has been offered. The proposed converter incorporates a half-bridge boost converter at the input port, an LCC resonant tank to aid in

Half-bridge Boost Bidirectional LCC Resonant $D C-D C$ Converter.

Microgrid application soft-switching switches and diodes, and lastly a voltage doubler circuit at the output port to double the voltage gain. Additionally, the $L C C$ resonant circuit provides the converter with a proper voltage gain. Thus, the converter's overall high voltage gain is achieved without the use of a transformer or a large number of multiplier circuits.

A novel three-level CLLC resonant converter for an off-board $E V$ charger has been suggested in order to accomplish bidirectional power transmission between the $D C$ microgrid and the $E V$. The

Two Three-level Full-Bridge CLLC Resonant Converters.
Off-board $E V$ charger proposed converter adapts to the wide voltage range of $E V s$, from 200 to $700 \mathrm{~V}$, by inserting resonant CLLC components and combining the working modes of the two three-level full bridges. Due to the totally symmetrical structure, this converter can work in two power directions, $G 2 V$ and $V 2 G$. 


\section{Challenges and Future Perspectives}

Numerous technical, economic, and other challenges must be overcome in order to make $D C-D C$ and $D C-A C$ converters popular and successful in a variety of applications. In this section, the challenges that may face some of the mentioned converters in terms of configuration and design are discussed.

- The $D A B-I B D C$ is one of the types of bidirectional converters, as mentioned above, and due to the advantages of $D A B-I B D C$, such as the ease of implementation of soft switching, bidirectional power transfer capabilities, modular and symmetric structure, and so on, they have garnered increasing attention in recent years. Numerous studies conducted globally so far have concentrated on fundamental characterization, topology and soft-switching solutions, control strategies, and hardware design and optimization. The design and performance optimization of DAB-IBDCs based on silicon carbide and gallium nitride $S i C / G a N$ power devices, as well as system-level $D A B-I B D C$ solutions for high-frequency link (HFL) power conversion systems, will be the trend in the future, with other major concerns including:

(1) Electrical optimization design methods of the topology, electrical parameters, and control approach of $D A B-I B D C$ s based on $S i C / G a N$ power devices in order to fully exploit their high-temperature, high-frequency, and low-loss properties. Mechanical optimization design methods of $D A B-I B D C$ s based on $\mathrm{SiC} / \mathrm{GaN}$ power devices in order to further increase the efficiency, power density, modularity, and reliability of $H F L$ power conversion systems.

(3) Multipurpose, modular, and intelligent HFL power conversion system solutions with high efficiency and high power density, which utilize $D A B$-IBDCs as the core circuit [172].

- Today's power converters must deliver increased power while maintaining high efficiency over a wide load range. As a result of the zero voltage switching (ZVS) for the primary side's MOSFETs or IGBTs and zero current switching (ZCS) for the secondary side's power devices, the $L L C$ resonant is a type of resonant converter topology that can address these challenges and is advantageous in front-end $D C-D C$ conversion applications. Additionally, it has a narrow switching frequency range to facilitate control, a quick transient response, and low cost because the leakage inductance of the transformer serves as the resonant inductor [173].

- The series resonant converter has become attractive for switched-mode power supply, not just because running at a high switching frequency increases power density, but also because of the decreased switching losses. In addition to its historical and technological significance, the resonant converter series has created a large family of high-density $D C / D C$ mode resonant converters, all of which have been widely used in several practical applications [174]. In the last few years, the growing interest in resonant power converters suggests more potential exploration of these converters. Although resonant converters have some superior features compared to conventional converters, studies have identified some issues that must be addressed to carry on [16]. To address the challenges facing the resonance part regardless of its type and structure, the assigned and selected parameters must be considered. The voltage gain, frequency ratio, load values, and inductance ratio must be understood. Finally, future studies should focus on the optimization of the control of such topologies.

- Power flow. One-directional power flow can be handled with a traditional buck-boost converter, but the power flow in bidirectional converters is in both directions. With bidirectional $D C-D C$ converters, voltage levels can be either stepped up or down based on the flow control capacity in either direction. According to galvanic isolation, there are two types of bidirectional converter: the first is the isolated bidirectional converter, and the second is the empty of isolation or non-isolated converter [35,175-177]. NIBDCs, as converters, require no high-frequency transformers to achieve electrical isolation between the load and the source; their efficiency in low-power applications 
is high because of the ease of controlling them, as well as their light weight [55]. On the other hand, an isolated bidirectional $D C-D C$ converter is necessary for several applications for the security of the source in case of an overloaded situation, as well as for noise reduction and voltage matching between conditions; therefore, it is employed in place of NIBDCs [37].

- Many studies have focused on the combination of resonance network type with IBDCs, including, but not limited to, SR-DAB, CLLC, CLLLC-type IBDC, and LLC. CLLC and $C L L L C$ resonant $I B D C$ s have attracted considerable attention due to their symmetrical characteristics in both the forward and reverse power flow directions. On the other hand, this structure faces difficulties because charging efficiency degrades dramatically when the battery voltage varies, and the frequency of the discharging operation varies widely [134]. In the $L L C-B D C$ structure, the $L L C$ resonant converter behaves similarly to a conventional series resonant converter with a very tight gain range, even though this type has better features than the earlier mentioned types, and is also extensively used in industry, especially in reverse power transfer [138]; this challenge must be considered in future perspectives. A bidirectional three-level $L L C$ resonant converter at fixed modulated frequency has been proposed by [178]; the proposed system can achieve a broad gain range even though the accurate analytical gain model is not derived. The system also used twelve switches, and because of this, the achievement of high efficiency over a wide gain range becomes a challenge to consider.

- Multilevel inverters (MLIs) are added to counter the problems associated with twolevel converters to meet the following criteria: (i) only sinusoidal output voltage shall be produced by the converter; (ii) the converter must have an output current of low THD. The advantage of MLIs is that the device voltage rating and the switching frequency can be significantly lower under the same output voltage compared to those of a conventional two-level converter; consequently, switching losses can be decreased remarkably, thereby improving the efficiency [32,179-181].

- Based on some industrial applications, such as drives, solar inverters, UPS, electric vehicles, and STATCOM, it is apparent that low-harmonic multilevel waveforms could attract the attention of industries to commercialize the most reliable and cost-effective topologies. However, it should be noted, however, that adding extra switches and auxiliary capacitors to the inverter structure increases the production cost. Adding new gate drivers, voltage balancing strategies, and switching algorithms to the control circuit will also complicate things. To be selected by a corporation to commercialize, there should be certain improvements on the topology, such as reduced size of the passive components, reduced switching frequency and switching losses, increased reliability, and efficiency. Industries are constantly attempting to find a balance between the number of levels and the complexity of design and operation [182]. It is seen that industries are looking for simplicity and high performance for their next generation of power electronic converters. The following are some of the possible future research and development challenges:

(1) Extending the use of single-DC-source $M L I$ topologies from high-power to medium- and low-power applications, such as aerospace and aircraft, power supply, home products, electrified transportation, solid-state transformers, and so on.

(2) Developing single- $D C$-source $M L I$ topologies at a higher level (more than five levels). In multiple-DC-source MLIs, one option is to replace the isolated $D C$ sources with voltage-controlled capacitors.

(3) By implementing novel voltage balancing techniques or external circuits, the size of auxiliary capacitors and voltage ripples in single- $D C$-source topologies can be reduced.

(4) Designing resonant converters based on single-DC-source MLIs.

(5) To decrease the complexity of the controllers, new switching techniques with integrated voltage balancing algorithms are being designed. 
The selection of the appropriate multilevel inverter $(M L I)$ topology has always been a challenge because it needs fewer switches and isolated $D C$ sources to generate a greater number of voltage levels. In comparison to multiple- $D C$-source $M L I$ topologies, single$D C$-source $M L C$ topologies are now considered more suitable for many power system applications, such as renewable energy $(R E)$ conversion systems and electrified transportation. Furthermore, the use of a single-DC-source $M L I$ to increase the power rating and minimize the switching frequency while maintaining acceptable power quality is an important necessity and a persistent challenge for the industry [182].

- In combining multilevel converters with bidirectional converters, the selection of a proper MLI topology and balancing the state-of-charges (SOCs) of batteries are the two key challenges in MLI-based battery storage systems (BSSs). MLIs are not only used in large-scale renewable energy-integrated grid applications, but also electric vehicle $(E V)$ charging, vehicle-to-grid $(V 2 G)$, and $E V$ operation. A challenging aspect of this field is the selection of an efficient and cost-effective MLI topology. The increasing use of MLIs in BSSs over the last ten years has advanced battery technologies, topologies, and control techniques. Voltage and SOC imbalances between battery packs could be a challenge in MLC-based BSSs due to electrochemical variations in battery packs and the use of second-life batteries [183]. The study by [184] presented an up-to-date study of the existing state-of-the-art MLC-based BSSs, taking into account the most recent contributions in the field of battery technology. Because of their long lifespan and high power density, Li-ion batteries are increasingly being used in MLI-based $B S S$ s. However, research on metal-air battery technology indicates that it is a viable candidate for $E V$ applications due to its high energy density and low cost. MLIs are already known to be superior to standard two- or three-level converter schemes due to their low harmonic distortion, small scale, and less reliance on magnetic circuits. This accounts for the increasing interest in MLIs over the last decade [184]. In summary, promising research directions for future work can include, but are not limited to:

(1) The creation of new types of MLIs with fewer components.

(2) Improving the PWM system and/or SOC balancing control to reduce the negative effects of voltage and SOC imbalances between battery packs.

(3) The incorporation of renewable energy sources, especially wind, into BSSs through $M L I s$ to mitigate the negative effects of $R E S s^{\prime}$ intermittent nature.

- A combination of both converters as previously mentioned in Section 6 can yield better performance, but the challenges remain. The study by [185] focused on the state of the art, challenges, and requirements of multilevel converters in industrial applications. To reduce energy waste and improve power quality, new highly efficient power electronic technologies and control strategies are required. There is enormous potential for energy efficiency improvement in electric motor-driven systems. Mediumvoltage $(M V)$ drives are widely used in several industries, such as the oil and gas industry, manufacturing plants, and process industries.

The topologies and control of line- and motor-side converters, as well as power semiconductor switching devices, are all challenges in the design of powered $M V$ drives. Three topologies have been successfully introduced as standard products for MV industrial drives by [185]: these include 3Level-NPC, 4Level-FLC, and 5 Level-CHB. However, the challenges facing this combination include:

(1) The suppression of $L C$ resonance and power quality; for current harmonic reduction or power factor compensation, the $L C$ line side resonant circuit is used. The capacitors form an $L C$ resonant circuit with the system's line inductance. The lightly damped $L C$ resonances can cause unwanted oscillations or overvoltage, which may demolish the power switches or other components in the rectifier circuits due to the low impedance of the $M V$ supply.

(2) Lowering the switching frequency generally increases the harmonic distortion of the drive's line and the waveforms of the motor side; hence, the optimal solution is 
sought. The challenge is to diminish waveform distortion while switching at a very low frequency (even below $100 \mathrm{~Hz}$ ).

Finally, integrated bidirectional resonant $D C-D C$ converters and multilevel inverters are expected to be well suited for industrial applications in the future. More studies are necessary for achieving a perfect level of reduction in the losses, number of components, size, and cost.

\section{Conclusions}

The aspects of bidirectional and resonant $D C-D C$ converters and multilevel inverters have been reviewed in this work to highlight the need to produce a combination of converters for grid-connected and energy storage applications. Each converter has been elaborated in various aspects, such as classifications, advantages, disadvantages, and their abilities to enhance energy conversion in modern energy systems. Based on this review, a soft-switching approach should be employed instead of hard switching to reduce and eliminate switching losses. RPC is a promising solution for EMI that occurs in PWM converters; it can increase efficiency and minimize the number of components. Bidirectional $D C-D C$ converters with galvanic isolation are more suitable for hybrid energy systems. In this study, comparisons have been made between different types of bidirectional converters and between multilevel and conventional inverters; the reviewed converters have also been compared in terms of their abilities to improve energy storage and grid connection integration. Lastly, the challenges in developing an efficient and combined multilevel resonant converter that can work under high voltage integration with soft-switching and bidirectional approaches have been elaborated. This article reviewed the significant contributions in the areas of bidirectional, multilevel, and resonant power converters with the intent of providing insight on the prospects in this study area. Therefore, producing and developing integrated bidirectional resonant multilevel converters are expected to meet the requirements of several industrial applications, such as electric vehicle charging, vehicle-togrid $(V 2 G)$, and medium-voltage $(M V)$ drives, due to their merits of reducing cost and size and their abilities to operate with high switching frequencies and less harmonic distortions.

Author Contributions: Conceptualization, S.A., M.S. and H.S.D.; methodology, A.B. and D.I.; writing-original draft preparation, S.A., M.S. and A.B.; investigation, D.I., M.S., M.A.N. and M.K.; resources, M.K. and A.B.; writing—review and editing, M.S., M.A.N. and S.A.; visualization, M.K. and H.S.D.; supervision, M.S. and D.I.; funding acquisition, M.K., M.S. and S.A. All authors have read and agreed to the published version of the manuscript.

Funding: This work was supported by Universiti Sains Malaysia.

Institutional Review Board Statement: Not applicable.

Informed Consent Statement: Not applicable.

Data Availability Statement: Not applicable.

Acknowledgments: The authors would like to express their gratitude to Universiti Sains Malaysia and the Research Creativity and Management Office (RCMO) for supporting and funding this research under short-term grant No. 304/PELECT/6315330.

Conflicts of Interest: The authors declare no conflict of interest.

\section{References}

1. Sinha, S.; Chandel, S. Review of recent trends in optimization techniques for solar photovoltaic-wind based hybrid energy systems. Renew. Sustain. Energy Rev. 2015, 50, 755-769. [CrossRef]

2. Khare, V.; Nema, S.; Baredar, P. Status of solar wind renewable energy in India. Renew. Sustain. Energy Rev. 2013, 27, 1-10. [CrossRef]

3. Viswanathan, B. Chapter 7—Solar Energy: Fundamentals. In Energy Sources; Viswanathan, B., Ed.; Elsevier: Amsterdam, The Netherlands, 2017; pp. 139-147.

4. Sivakumar, S.; Sathik, M.J.; Manoj, P.; Sundararajan, G. An assessment on performance of DC-DC converters for renewable energy applications. Renew. Sustain. Energy Rev. 2016, 58, 1475-1485. [CrossRef] 
5. Eccher, M.; Salemi, A.; Turrini, S.; Brusa, R. Measurements of power transfer efficiency in CPV cell-array models using individual DC-DC converters. Appl. Energy 2015, 142, 396-406. [CrossRef]

6. Duran, E.; Andujar, J.; Segura, F.; Barragan, A. A high-flexibility DC load for fuel cell and solar arrays power sources based on DC-DC converters. Appl. Energy 2011, 88, 1690-1702. [CrossRef]

7. Saravanan, S.; Babu, N.R. Analysis and implementation of high step-up DC-DC converter for PV based grid application. Appl. Energy 2017, 190, 64-72. [CrossRef]

8. Zhang, N.; Sutanto, D.; Muttaqi, K.M. A review of topologies of three-port DC-DC converters for the integration of renewable energy and energy storage system. Renew. Sustain. Energy Rev. 2016, 56, 388-401. [CrossRef]

9. Outeiro, M.T.; Visintini, R.; Buja, G. Considerations in Designing Power Supplies for Particle Accelerators. In Proceedings of the IECON 2013-39th Annual Conference of the IEEE Industrial Electronics Society, Vienna, Austria, 10-13 November 2013; pp. 7076-7081.

10. Outeiro, M.T.; Buja, G.; Carvalho, A. Resonant Converters for Electric Equipment Power Supply. In Proceedings of the IECON 201440th Annual Conference of the IEEE Industrial Electronics Society, Dallas, TX, USA, 29 October-1 November 2014 ; pp. 5065-5071.

11. Richelli, A.; Salem, M.; Colalongo, L. A Review of Fully Integrated and Embedded Power Converters for IoT. Energies 2021, 14, 5419. [CrossRef]

12. Monsalve-Rueda, M.; Candelo-Becerra, J.E.; Hoyos, F.E. Dynamic Behavior of a Sliding-Mode Control Based on a Washout Filter with Constant Impedance and Nonlinear Constant Power Loads. Appl. Sci. 2019, 9, 4548. [CrossRef]

13. Ali, A.I.M.; Sayed, M.A.; Takeshita, T. Isolated single-phase single-stage DC-AC cascaded transformer-based multilevel inverter for stand-alone and grid-tied applications. Int. J. Electr. Power Energy Syst. 2021, 125, 106534. [CrossRef]

14. Hrigua, S.; Costa, F.; Gautier, C.; Revol, B. New Method of EMI Analysis in Power Electronics Based on Semiconductors Transient Models: Application to SiC MOSFET/Schottky Diode. In Proceedings of the IECON 2012-38th Annual Conference on IEEE Industrial Electronics Society, Montreal, QC, Canada, 25-28 October 2012; pp. 590-595.

15. Britto, K.A.; Dhanasekaran, R.; Vimala, R.; Saranya, B. EMI Analysis and Evaluation of an Improved Flyback Converter. In Proceedings of the 2012 International Conference on Computer Communication and Informatics, Coimbatore, India, 10-12 January 2012; pp. 1-7.

16. Salem, M.; Jusoh, A.; Idris, N.R.N.; Das, H.S.; Alhamrouni, I. Resonant power converters with respect to passive storage (LC) elements and control techniques-An overview. Renew. Sustain. Energy Rev. 2018, 91, 504-520. [CrossRef]

17. Ravi, D.; Reddy, B.M.; Shimi, S.; Samuel, P. Bidirectional dc to dc Converters: An Overview of Various Topologies, Switching Schemes and Control Techniques. Int. J. Eng. Technol. 2018, 7, 360-365. [CrossRef]

18. Gorji, S.A.; Sahebi, H.G.; Ektesabi, M.; Rad, A.B. Topologies and control schemes of bidirectional DC-DC power converters: An Overview. IEEE Access 2019, 7, 117997-118019. [CrossRef]

19. Samsudin, N.A.; Ishak, D. Full-bridge LLC Resonant High-voltage DC-DC Converter with Hybrid Symmetrical Voltage Multiplier. IETE J. Res. 2021, 67, 687-698. [CrossRef]

20. Salem, M.; Jusoh, A.; Idris, N.N.; Sutikno, T.; Buswig, Y.M. Phase-shifted series resonant converter with zero voltage switching turn-on and variable frequency control. Int. J. Power Electron. Drive Syst. (IJPEDS) 2017, 8, 1184-1192. [CrossRef]

21. Li, Z.; Xue, B.; Wang, H. An interleaved secondary-side modulated LLC resonant converter for wide output range applications. IEEE Trans. Ind. Electron. 2019, 67, 1124-1135. [CrossRef]

22. Alhamrouni, I.; Hamzah, M.B.; Salem, M.; Jusoh, A.; Khairuddin, A.B.; Sutikno, T. A bidirectional resonant converter based on wide input range and high efficiency for photovoltaic application. Int. J. Power Electron. Drive Syst. 2019, 10, 1469. [CrossRef]

23. Rashid, M.H. Power Electronics Handbook; Butterworth-Heinemann: Oxford, UK, 2018.

24. Kabalci, E. Multilevel Inverters: Control Methods and Advanced Power Electronic Applications; Elsevier: Amsterdam, The Netherlands, 2021.

25. Dokić, B.L.; Blanuša, B. Introduction to Multilevel Converters. In Power Electronics; Springer: Berlin/Heidelberg, Germany, 2015; pp. 559-592.

26. Salem, M.; Yahya, K. Resonant Power Converters. In Electric Power Conversion; IntechOpen: London, UK, 2019.

27. Pan, L.; Zhang, C. An integrated multifunctional bidirectional AC/DC and DC/DC converter for electric vehicles applications. Energies 2016, 9, 493. [CrossRef]

28. Wei, Y.; Luo, Q.; Du, X.; Altin, N.; Nasiri, A.; Alonso, J.M. A dual half-bridge LLC resonant converter with magnetic control for battery charger application. IEEE Trans. Power Electron. 2019, 35, 2196-2207. [CrossRef]

29. Oliveira, F.J.d.; Ribeiro, E.K.d.B.; Luiz, A.-S.A.; Stopa, M.M. Study and Implementation of a High Gain Bidirectional Dc-Dc Converter for Photovoltaic on-Grid Systems. In Proceedings of the 2017 IEEE 8th International Symposium on Power Electronics for Distributed Generation Systems (PEDG), Florianopolis, Brazil, 17-20 April 2017; pp. 1-8.

30. Costa, L.; Buticchi, G.; Liserre, M. Bidirectional Series-Resonant DC-DC Converter with Fault-Tolerance Capability for Smart Transformer. In Proceedings of the 2016 IEEE Energy Conversion Congress and Exposition (ECCE), Milwaukee, WI, USA, 18-22 September 2016; pp. 1-7.

31. Karshenas, H.R.; Daneshpajooh, H.; Safaee, A.; Jain, P.; Bakhshai, A. Bidirectional dc-dc converters for energy storage systems. In Energy Storage in the Emerging Era of Smart Grids; IntechOpen: London, UK, 2011; Volume 18.

32. Han, S.-H.; Kim, H.-G.; Cha, H.; Chun, T.-W.; Nho, E.-C. Bi-directional multi-level converter for an energy storage system. J. Power Electron. 2014, 14, 499-506. [CrossRef] 
33. Wang, S.; Zheng, Z.; Li, C.; Xu, L.; Wang, K.; Li, Y. Accurate frequency-domain analysis and hybrid control method for isolated dual active bridge series resonant DC /DC converters. IET Power Electron. 2019, 12, 2932-2941. [CrossRef]

34. Bai, H.; Mi, C. Eliminate reactive power and increase system efficiency of isolated bidirectional dual-active-bridge DC-DC converters using novel dual-phase-shift control. IEEE Trans. Power Electron. 2008, 23, 2905-2914. [CrossRef]

35. Zhifu, W.; Yupu, W.; Yinan, R. Design of closed-loop control system for a bidirectional full bridge DC/DC converter. Appl. Energy 2017, 194, 617-625. [CrossRef]

36. Pramanik, R.; Pati, B. Modelling and Control of a Non-isolated Half-bridge Bidirectional DC-DC Converter with an Energy Management Topology Applicable with EV/HEV. J. King Saud Univ.-Eng. Sci. 2021. [CrossRef]

37. Reddy, B.M.; Samuel, P. Analysis of Isolated Bi-Directional dc-dc Converters for Performance Enhancement of PV System and Energy Storage System. In Proceedings of the PIICON-2016, Government Engineering College, Bikaner, India, 25-27 November 2016.

38. Tytelmaier, K.; Husev, O.; Veligorskyi, O.; Yershov, R. A Review of Non-Isolated Bidirectional Dc-Dc Converters for Energy Storage Systems. In Proceedings of the International Young Scientists Forum on Applied Physics and Engineering (YSF), Kharkiv, Ukraine, 10-14 October 2016; pp. 22-28.

39. Khodabakhsh, J.; Moschopoulos, G. A Study of Multilevel Resonant DC-DC Converters for Conventional DC Voltage Bus Applications. In Proceedings of the IEEE Applied Power Electronics Conference and Exposition (APEC), San Antonio, TX, USA, 4-8 March 2018; pp. 2135-2141.

40. Gupta, A.K.; Kumar, D.; Reddy, B.M.; Samuel, P. BBBC Based Optimization of PI Controller Parameters for Buck Converter. In Proceedings of the Innovations in Power and Advanced Computing Technologies (i-PACT), Vellore, India, 21-22 April 2017; pp. 1-6.

41. Stahl, G.; Rodriguez, M.; Maksimovic, D. A High-Efficiency Bidirectional Buck-Boost DC-DC Converter. In Proceedings of the Twenty-Seventh Annual IEEE Applied Power Electronics Conference and Exposition (APEC), Orlando, FL, USA, 5-9 February 2012; pp. 1362-1367.

42. Shahin, M. Analysis of Bidirectional SEPIC/Zeta Converter with Coupled Inductor. In Proceedings of the International Conference on Technological Advancements in Power and Energy (TAP Energy), Kollam, India, 24-26 June 2015; pp. 103-108.

43. Mohammadi, M.R.; Farzanehfard, H. A New Bidirectional ZVS-PWM Cuk Converter with Active Clamp. In Proceedings of the 19th Iranian Conference on Electrical Engineering, Tehran, Iran, 17-19 May 2011; pp. 1-6.

44. Tank, S.B.; Manavar, K.; Adroja, N. Non-Isolated Bi-directional DC-DC Converters for Plug-In Hybrid Electric Vehicle Charge Station Application. In Proceedings of the Emerging Trends in Computer \& Electrical Engineering (ETCEE 2015), Rajkot, India, 13-14 March 2015.

45. Zhang, H.; Chen, Y.; Park, S.-J.; Kim, D.-H. A Family of Bidirectional DC-DC Converters for Battery Storage System with High Voltage Gain. Energies 2019, 12, 1289. [CrossRef]

46. Devaraju, B.; Ramasubramanian, J. An enhanced cascaded topology of non-isolated bidirectional DC-DC converter with switched coupled inductor. Int. Rev. Model. Simul. 2013, 6, 1371-1382.

47. Thi Kim Nga, T.; Park, S.-M.; Park, Y.-J.; Park, S.-H.; Kim, S.; Van Cong Thuong, T.; Lee, M.; Hwang, K.C.; Yang, Y.; Lee, K.-Y. A Wide Input Range Buck-Boost DC-DC Converter Using Hysteresis Triple-Mode Control Technique with Peak Efficiency of $94.8 \%$ for RF Energy Harvesting Applications. Energies 2018, 11, 1618. [CrossRef]

48. Lee, H.S.; Yun, J.J. High-Efficiency Bidirectional Buck-Boost Converter for Photovoltaic and Energy Storage Systems in a Smart Grid. IEEE Trans. Power Electron. 2019, 34, 4316-4328. [CrossRef]

49. Zhang, Y.; Gao, Y.; Zhou, L.; Sumner, M. A switched-capacitor bidirectional DC-DC converter with wide voltage gain range for electric vehicles with hybrid energy sources. IEEE Trans. Power Electron. 2018, 33, 9459-9469. [CrossRef]

50. Sakulchotruangdet, S.; Khwan-On, S. Three-phase interleaved boost converter with fault tolerant control strategy for renewable energy system applications. Procedia Comput. Sci 2016, 86, 353-356. [CrossRef]

51. Huang, X.; Lee, F.C.; Li, Q.; Du, W. High-frequency high-efficiency GaN-based interleaved CRM bidirectional buck/boost converter with inverse coupled inductor. IEEE Trans. Power Electron. 2016, 31, 4343-4352. [CrossRef]

52. Yang, Y.; Ma, J.; Ho, C.N.-M.; Zou, Y. A new coupled-inductor structure for interleaving bidirectional DC-DC converters. IEEE J. Emerg. Sel. Top. Power Electron. 2015, 3, 841-849. [CrossRef]

53. Thiyagarajan, A.; Kumar, S.P.; Nandini, A. Analysis and Comparison of Conventional and Interleaved DC/DC Boost Converter. In Proceedings of the Second International Conference on Current Trends in Engineering and Technology-ICCTET, Coimbatore, India, 8 July 2014; pp. 198-205.

54. Wang, F.; Luo, Y.; Li, H.; Xu, X. Switching characteristics optimization of two-phase interleaved bidirectional DC/DC for electric vehicles. Energies 2019, 12, 378. [CrossRef]

55. Reddy, B.M.; Samuel, P. A Comparative Analysis of Non-Isolated Bi-Directional Dc-Dc Converters. In Proceedings of the IEEE 1st International Conference on Power Electronics, Intelligent Control and Energy Systems (ICPEICES), Delhi, India, 4-6 July 2016; pp. 1-6.

56. Joshi, M.C.; Samanta, S. Modeling and Control of Bidirectional DC-DC Converter Fed PMDC Motor for Electric Vehicles. In Proceedings of the Annual IEEE India Conference (INDICON), Mumbai, India, 13-15 December 2013; pp. 1-6.

57. Bodravara, N.; Malapur, S.; Shruthi, M.B. Davanagere, Comparison of Isolated and Non-Isolated Bidirectional DC-DC Converter Fed PMDC Motor. Int. J. Res. Appl. Sci. Eng. Technol. (IJRASET) 2015, 3, 698-702. 
58. Lee, J.; Jeong, Y.; Han, B. A Two-Stage Isolated/Bidirectional DC/DC Converter With Current Ripple Reduction Technique. IEEE Trans. Ind. Electron. 2012, 59, 644-646. [CrossRef]

59. Kashif, M. Bidirectional Flyback DC-DC Converter for Hybrid Electric Vehicle: Utility, Working and PSPICE Computer Model. In Proceedings of the Asia Pacific Conference on Postgraduate Research in Microelectronics and Electronics, Hyderabad, India, 5-7 December 2012; pp. 61-66.

60. Shen, C.-L.; Shen, Y.-S.; Tsai, C.-T. Isolated DC-DC Converter for Bidirectional Power Flow Controlling with Soft-Switching Feature and High Step-Up/Down Voltage Conversion. Energies 2017, 10, 296. [CrossRef]

61. Wu, Y.-E.; Ke, Y.-T. A Novel Bidirectional Isolated DC-DC Converter with High Voltage Gain and Wide Input Voltage. IEEE Trans. Power Electron 2021, 36, 7973-7985. [CrossRef]

62. Hirose, T.; Matsuo, H. A Consideration of Bidirectional Superposed Dual Active Bridge Dc-Dc Converter. In Proceedings of the 2nd International Symposium on Power Electronics for Distributed Generation Systems, Hefei, China, 16-18 June 2010; pp. 39-46.

63. Pan, X.; Li, H.; Liu, Y.; Zhao, T.; Ju, C.; Rathore, A.K. An overview and comprehensive comparative evaluation of current-fedisolated-bidirectional DC/DC converter. IEEE Trans. Power Electron. 2019, 35, 2737-2763. [CrossRef]

64. He, P.; Khaligh, A. Comprehensive analyses and comparison of $1 \mathrm{~kW}$ isolated DC-DC converters for bidirectional EV charging systems. IEEE Trans. Transp. Electrif. 2017, 3, 147-156. [CrossRef]

65. Higa, H.; Takuma, S.; Orikawa, K.; Itoh, J.-i. Dual Active Bridge DC-DC Converter Using Both Full and Half Bridge Topologies to Achieve High Efficiency for Wide Load. In Proceedings of the IEEE Energy Conversion Congress and Exposition (ECCE), Montreal, QC, Canada, 20-24 September 2015; pp. 6344-6351.

66. Doncker, R.W.A.A.D.; Divan, D.M.; Kheraluwala, M.H. A three-phase soft-switched high-power-density DC/DC converter for high-power applications. IEEE Trans. Ind. Appl. 1991, 27, 63-73. [CrossRef]

67. Solero, L.; Caricchi, F.; Crescimbini, F.; Honorati, O.; Mezzetti, F. Performance of a $10 \mathrm{~kW}$ Power Electronic Interface for Combined Wind/PV Isolated Generating Systems. In Proceedings of the PESC Record, 27th Annual IEEE Power Electronics Specialists Conference, Baveno, Italy, 23-27 June 1996; Volume 2, pp. 1027-1032.

68. Kheraluwala, M.N.; Gascoigne, R.W.; Divan, D.M.; Baumann, E.D. Performance characterization of a high-power dual active bridge DC-to-DC converter. IEEE Trans. Ind. Appl. 1992, 28, 1294-1301. [CrossRef]

69. Peng, F.Z.; Li, H.; Su, G.-J.; Lawler, J.S. A new ZVS bidirectional DC-DC converter for fuel cell and battery application. IEEE Trans. Power Electron. 2004, 19, 54-65. [CrossRef]

70. Chub, A.; Vinnikov, D.; Kosenko, R.; Liivik, E.; Galkin, I. Bidirectional DC-DC converter for modular residential battery energy storage systems. IEEE Trans. Ind. Electron. 2019, 67, 1944-1955. [CrossRef]

71. Gorji, S.A.; Mostaan, A.; Tran My, H.; Ektesabi, M. Non-isolated buck-boost DC-DC converter with quadratic voltage gain ratio. IET Power Electron. 2019, 12, 1425-1433. [CrossRef]

72. Xiong, H.; Song, D.; Shi, F.; Wei, Y.; Jinzhen, L. Novel voltage equalisation circuit of the lithium battery pack based on bidirectional flyback converter. IET Power Electron. 2020, 13, 2194-2200. [CrossRef]

73. Gorji, S.; Ektesabi, M.; Zheng, J. Isolated switched-boost push-pull DC-DC converter for step-up applications. IET Electron. Lett. 2017, 53, 177-179. [CrossRef]

74. Abdul-Hakeem, M.D.; Sahid, M.R.; Sutikno, T. Overview of soft-switching DC-DC converters. Int. J. Power Electron. Drive Syst. 2018, 9, 2006.

75. Mohan, N.; Undeland, T.M.; Robbins, W.P. Power Electronics: Converters, Applications, and Design; John Wiley \& Sons: Hoboken, NJ, USA, 2007.

76. Hui, S.R.; Chung, H.S. Resonant and soft-switching converters. In Power Electronics Handbook; Elsevier: Amsterdam, The Netherlands, 2011; pp. 409-453.

77. Luo, J.; Wang, J.; Fang, Z.; Shao, J.; Li, J. Optimal design of a high efficiency LLC resonant converter with a narrow frequency range for voltage regulation. Energies 2018, 11, 1124. [CrossRef]

78. Hart, D.W. Power Electronics; Tata McGraw-Hill Education: New York, NY, USA, 2011.

79. Hui, S.R.; Chung, H.S. Resonant and Soft-Switching in Power Electronics Handbook, 3rd ed.; Elsevier Inc.: Oxford, UK, 2011; pp. 409-453.

80. Outeiro, M.T.; Buja, G.; Czarkowski, D. Resonant Power Converters: An Overview with Multiple Elements in the Resonant Tank Network. IEEE Ind. Electron. Mag. 2016, 10, 21-45. [CrossRef]

81. Salem, M.; Jusoh, A.; Rumzi, N.; Idris, N.; Alhamrouni, I. Steady state and generalized state space averaging analysis of the series resonant converter. In Proceedings of the 3rd IET International Conference on Clean Energy and Technology (CEAT) 2014, Kuching, China, 24-26 November 2014; pp. 1-5.

82. Chuang, Y.; Ke, Y.; Chuang, H.; Chen, H. Implementation and Analysis of an Improved Series-Loaded Resonant DC-DC Converter Operating Above Resonance for Battery Chargers. IEEE Trans. Ind. Appl. 2009, 45, 1052-1059. [CrossRef]

83. Ivensky, G.; Bronshtein, S.; Abramovitz, A. Approximate Analysis of Resonant LLC DC-DC Converter. IEEE Trans. Power Electron. 2011, 26, 3274-3284. [CrossRef]

84. Kazimierczuk, M.K.; Czarkowski, D. Resonant Power Converters; John Wiley \& Sons: Hoboken, NJ, USA, 2012.

85. Salem, M.; Jusoh, A.; Idris, N.N.; Sutikno, T.; Abid, I. ZVS full bridge series resonant boost converter with series-connected transformer. Int. J. Power Electron. Drive Syst. 2017, 8, 812. [CrossRef] 
86. Outeiro, M.T.; Buja, G. Comparison of Resonant Power Converters with Two, Three, and Four Energy Storage Elements. In Proceedings of the IECON-41st Annual Conference of the IEEE Industrial Electronics Society, Yokohama, Japan, 9-12 November 2015; pp. 001406-001411.

87. Salem, M.; Jusoh, A.; Idris, N.R.N.; Alhamrouni, I. Performance Study of Series Resonant Converter Using Zero Voltage Switching. In Proceedings of the IEEE Conference on Energy Conversion (CENCON), Johor Bahru, Malaysia, 13-14 October 2014; pp. 96-100.

88. Salem, M.; Ramachandaramurthy, V.K.; Sanjeevikumar, P.; Leonowicz, Z.; Yaramasu, V. Full Bridge LLC Resonant Three-Phase Interleaved Multi Converter for HV Applications. In Proceedings of the 2019 IEEE International Conference on Environment and Electrical Engineering and 2019 IEEE Industrial and Commercial Power Systems Europe (EEEIC/I\&CPS Europe), Genova, Italy, 11-14 June 2019; pp. 1-6.

89. Tan, X.; Ruan, X. Equivalence Relations of Resonant Tanks: A New Perspective for Selection and Design of Resonant Converters. IEEE Trans. Ind. Electron. 2016, 63, 2111-2123. [CrossRef]

90. Salem, M.; Jusoh, A.; Idris, N.R.N.; Alhamrouni, I. Comparison of LCL Resonant Converter with Fixed Frequency, and Variable Frequency Controllers. In Proceedings of the 2017 IEEE Conference on Energy Conversion (CENCON), Kuala Lumpur, Malaysia, 30-31 October 2017; pp. 84-89.

91. Zhang, W.; Wong, S.; Tse, C.K.; Chen, Q. Design for Efficiency Optimization and Voltage Controllability of Series-Series Compensated Inductive Power Transfer Systems. IEEE Trans. Power Electron. 2014, 29, 191-200. [CrossRef]

92. Severns, R.P. Topologies for three-element resonant converters. IEEE Trans. Power Electron. 1992, 7, 89-98. [CrossRef]

93. Zeng, J.; Zhang, G.; Yu, S.S.; Zhang, B.; Zhang, Y. LLC resonant converter topologies and industrial applications-A review. Chin. J. Electr. Eng. 2020, 6, 73-84. [CrossRef]

94. Almardy, M.; Bhat, A.K. Three-phase fixed-frequency interleaved (LC)(L)-type series-resonant converter with a capacitive output filter. J. Eng. 2019, 2019, 4178-4184. [CrossRef]

95. Patil, U.; Harischandrappa, N. Performance evaluation of high-frequency CLL resonant DC-DC converter operated with phase-shift and modified PWM gating scheme: Analysis, design and implementation. IET Power Electron. 2020, 13, 2127-2138. [CrossRef]

96. Ahn, S.-H.; Jang, S.-R.; Ryoo, H.-J. High-efficiency bidirectional three-phase LCC resonant converter with a wide load range. IEEE Trans. Power Electron. 2019, 34, 97-105. [CrossRef]

97. Lin, B.-R.; Hou, B.-R. Analysis and implementation of a zero-voltage switching pulse-width modulation resonant converter. IET Power Electron. 2014, 7, 148-156. [CrossRef]

98. Lin, B.; Chao, C. Soft-Switching Converter with Two Series Half-Bridge Legs to Reduce Voltage Stress of Active Switches. IEEE Trans. Ind. Electron. 2013, 60, 2214-2224. [CrossRef]

99. Tarter, R.E. Solid-State Power Conversion Handbook; John Wiley \& Sons: Hoboken, NJ, USA, 1993.

100. Hassan, J.; Bae, C.-K.; Lim, J.-W.; Kim, M. High Step-Up Quasi-Resonant Converter Featuring Minimized Switching Loss Over Wide Input Voltage Range. IEEE Trans. Ind. Electron 2021, 68, 10784-10795. [CrossRef]

101. Costa, L.F.; Buticchi, G.; Liserre, M. A Family of Series-Resonant DC-DC Converter With Fault-Tolerance Capability. IEEE Trans. Ind. Appl. 2018, 54, 335-344. [CrossRef]

102. Bhat, A.K.S.; Dewan, S.B. A generalized approach for the steady-state analysis of resonant inverters. IEEE Trans. Ind. Appl. 1989, 25, 326-338. [CrossRef]

103. Bhat, A.K.S. A resonant converter suitable for $650 \mathrm{~V}$ DC bus operation. IEEE Trans. Power Electron. 1991, 6, 739-748. [CrossRef]

104. Steigerwald, R.L. A comparison of half-bridge resonant converter topologies. IEEE Trans. Power Electron. 1988, 3, 174-182. [CrossRef]

105. Erickson, R.W.M. Dragan, Fundamentals of Power Electronics, 3rd ed.; Springer: Berlin/Heidelberg, Germany, 2020.

106. Schupbach, R.M.; Balda, J.C. Comparing DC-DC Converters for Power Management in Hybrid Electric Vehicles. In Proceedings of the IEEE International Electric Machines and Drives Conference, IEMDC'03, Madison, WI, USA, 1-4 June 2003; Volume 3, pp. 1369-1374.

107. Bhat, A.K.S. A 48 V Output DC-to-DC Resonant Converter Suitable for Telecommunication Applications. In Proceedings of the Eleventh International Telecommunications Energy Conference, Florence, Italy, 15-18 October 1989; Volume 2, pp. 20.4/1-20.4/8.

108. Salem, M.; Jusoh, A.; Dahidah, M.; Ishak, D.; Richelli, A.; Alhamroni, I.; Kamarol, M. Improved topology of three-phase series resonant DC-DC boost converter with variable frequency control. Alex. Eng. J. 2021. [CrossRef]

109. Bhat, A.K. A unified approach for the steady-state analysis of resonant converters. IEEE Trans. Ind. Electron. 1991, 38, 251-259. [CrossRef]

110. Nabae, A.; Takahashi, I.; Akagi, H. A New Neutral-Point-Clamped PWM Inverter. IEEE Trans. Ind. Appl. 1981, IA-17, 518-523. [CrossRef]

111. Abd Halim, W.; Ganeson, S.; Azri, M.; Azam, T.T. Review of multilevel inverter topologies and its applications. J. Telecommun. Electron. Comput. Eng. (JTEC) 2016, 8, 51-56.

112. Omar, R.; Rasheed, M.; Sulaiman, M.; Tamijis, M. Comparative Study of a Three Phase Cascaded H-Bridge Multilevel Inverter for Harmonic Reduction. TELKOMNIKA Indones. J. Electr. Eng. 2015, 14, 481-492. [CrossRef]

113. Krishna, R.A.; Suresh, L.P. A Brief Review on Multi Level Inverter Topologies. In Proceedings of the International Conference on Circuit, Power and Computing Technologies (ICCPCT), Nagercoil, India, 18-19 March 2016; pp. 1-6.

114. Koshti, A.K.; Rao, M.N. A Brief Review on Multilevel Inverter Topologies. In Proceedings of the International Conference on Data Management, Analytics and Innovation (ICDMAI), Pune, India, 24-26 February 2017; pp. 187-193. 
115. Prasad, K.N.V.; Kumar, G.R.; Kiran, T.V.; Narayana, G.S. Comparison of Different Topologies of Cascaded H-Bridge Multilevel Inverter. In Proceedings of the International Conference on Computer Communication and Informatics, Coimbatore, India, 4-6 January 2013; pp. 1-6.

116. Siddique, M.D.; Mekhilef, S.; Shah, N.M.; Sarwar, A.; Iqbal, A.; Memon, M.A. A new multilevel inverter topology with reduce switch count. IEEE Access 2019, 7, 58584-58594. [CrossRef]

117. Kala, P.; Arora, S. A comprehensive study of classical and hybrid multilevel inverter topologies for renewable energy applications. Renew. Sustain. Energy Rev. 2017, 76, 905-931. [CrossRef]

118. Hassan, A.; Yang, X.; Chen, W.; Houran, M.A. A State of the Art of the Multilevel Inverters with Reduced Count Components. Electronics 2020, 9, 1924. [CrossRef]

119. Bughneda, A.; Salem, M.; Richelli, A.; Ishak, D.; Alatai, S. Review of Multilevel Inverters for PV Energy System Applications. Energies 2021, 14, 1585. [CrossRef]

120. Rathore, S.; Kirar, M.K.; Bhardwaj, S. Simulation of cascaded H-bridge multilevel inverter using PD, POD, APOD techniques. Electr. Comput. Eng. Int. J. (ECIJ) 2015, 4, 27-41. [CrossRef]

121. Rodriguez, J.; Jih-Sheng, L.; Fang Zheng, P. Multilevel inverters: A survey of topologies, controls, and applications. IEEE Trans. Ind. Electron. 2002, 49, 724-738. [CrossRef]

122. Srinivasan, G.K.; Rivera, M.; Loganathan, V.; Ravikumar, D.; Mohan, B. Trends and Challenges in Multi-Level Inverter with Reduced Switches. Electronics 2021, 10, 368. [CrossRef]

123. Abu-Rub, H.; Malinowski, M.; Al-Haddad, K. Power Electronics for Renewable Energy Systems, Transportation and Industrial Applications; John Wiley \& Sons: West Sussex, UK, 2014.

124. Meynard, T.A.; Foch, H. Multi-Level Conversion: High Voltage Choppers and Voltage-Source Inverters. In Proceedings of the PESC ‘92 Record, 23rd Annual IEEE Power Electronics Specialists Conference, Toledo, Spain, 29 June-3 July 1992; Volume 1, pp. 397-403.

125. Jih-Sheng, L.; Fang Zheng, P. Multilevel converters-a new breed of power converters. IEEE Trans. Ind. Appl. 1996, 32, 509-517. [CrossRef]

126. Shanono, I.H.; Abdullah, N.R.H.; Muhammad, A. A survey of multilevel voltage source inverter topologies, controls, and applications. Int. J. Power Electron. Drive Syst. 2018, 9, 1186. [CrossRef]

127. Lavieville, J.-P.; Carrere, P.; Meynard, T. Electronic Circuit for Converting Electrical Energy, and A Power Supply Installation Making Use Thereof. U.S. Patent 5,668,711, 16 September 1997.

128. Subarnan, J.G. Multilevel Inverters: An Enabling Technology. In Hybrid-Renewable Energy Systems in Microgrids; Elsevier: Amsterdam, The Netherlands, 2018; pp. 61-80.

129. Baker, R.H.; Bannister, L.H. Electric Power Converter. U.S. Patent 3,867,643, 18 February 1975.

130. Marchesoni, M. High-performance current control techniques for application to multilevel high-power voltage source inverters. IEEE Trans. Power Electron. 1992, 7, 189-204. [CrossRef]

131. Prabaharan, N.; Palanisamy, K. A comprehensive review on reduced switch multilevel inverter topologies, modulation techniques and applications. Renew. Sustain. Energy Rev. 2017, 76, 1248-1282. [CrossRef]

132. Zhang, C.; Li, P.; Guo, Y. Bidirectional DC/DC and SOC drooping control for DC Microgrid Application. Electronics 2020, 9, 225. [CrossRef]

133. Shen, Y.; Wang, H.; Al-Durra, A.; Qin, Z.; Blaabjerg, F. A Bidirectional Resonant DC-DC Converter Suitable for Wide Voltage Gain Range. IEEE Trans. Power Electron. 2018, 33, 2957-2975. [CrossRef]

134. Zahid, Z.U.; Dalala, Z.M.; Chen, R.; Chen, B.; Lai, J.-S. Design of bidirectional DC-DC resonant converter for vehicle-to-grid (V2G) applications. IEEE Trans. Transp. Electrif. 2015, 1, 232-244. [CrossRef]

135. Jiang, T.; Zhang, J.; Wu, X.; Sheng, K.; Wang, Y. A Bidirectional LLC Resonant Converter With Automatic Forward and Backward Mode Transition. IEEE Trans. Power Electron. 2015, 30, 757-770. [CrossRef]

136. Kim, N.-G.; Jo, S.-W.; Han, B.; Choi, H.H.; Kim, M. Highly Efficient Bidirectional Current-Fed Resonant Converter Over Wide Voltage Gain Range. IEEE Trans. Ind. Electron. 2021, 68, 10913-10927. [CrossRef]

137. Wu, H.; Sun, K.; Li, Y.; Xing, Y. Fixed-frequency PWM-controlled bidirectional current-fed soft-switching series-resonant converter for energy storage applications. IEEE Trans. Ind. Electron. 2017, 64, 6190-6201. [CrossRef]

138. Musavi, F.; Craciun, M.; Gautam, D.S.; Eberle, W.; Dunford, W.G. An LLC resonant DC-DC converter for wide output voltage range battery charging applications. IEEE Trans. Power Electron. 2013, 28, 5437-5445. [CrossRef]

139. Rahman, A.N.; Lee, C.-Y.; Chiu, H.-J.; Hsieh, Y.-C. Bidirectional Three-Phase LLC Resonant Converter. In Proceedings of the IEEE Transportation Electrification Conference and Expo, Asia-Pacific (ITEC Asia-Pacific), Bangkok, Thailand, 6-9 June 2018; pp. 1-5.

140. Kim, D.-H.; Kim, M.-S.; Hussain Nengroo, S.; Kim, C.-H.; Kim, H.-J. LLC Resonant Converter for LEV (Light Electric Vehicle) Fast Chargers. Electronics 2019, 8, 362. [CrossRef]

141. Monteiro, V.D.F.; Pinto, J.; Ferreira, J.C.; Gonçalves, H.; Afonso, J.L. Bidirectional multilevel converter for electric vehicles. In Proceedings of the Annual Seminar on Automation, Industrial Electronics and Instrumentation, SAAEI'12, Guimarães, Portugal, 11-13 July 2012; pp. 434-439.

142. Busquets-Monge, S.; Alepuz, S.; Bordonau, J. A bidirectional multilevel boost-buck DC-DC converter. IEEE Trans. Power Electron. 2011, 26, 2172-2183. [CrossRef] 
143. Shukla, A.; Ghosh, A.; Joshi, A. Control of dc capacitor voltages in diode-clamped multilevel inverter using bidirectional buck-boost choppers. IET Power Electron. 2012, 5, 1723-1732. [CrossRef]

144. Calais, M.; Borle, L.J.; Agelidis, V.G. Analysis of Multicarrier PWM Methods for A Single-Phase Five Level Inverter. In Proceedings of the IEEE 32nd Annual Power Electronics Specialists Conference (IEEE Cat. No. 01CH37230), Vancouver, BC, Canada, 17-21 June 2001; pp. 1351-1356.

145. Awal, M.; Bipu, M.R.H.; Montes, O.A.; Feng, H.; Husain, I.; Yu, W.; Lukic, S. Capacitor Voltage Balancing for Neutral Point Clamped Dual Active Bridge Converters. IEEE Trans. Power Electron. 2020, 35, 11267-11276. [CrossRef]

146. Chen, A.; Hu, L.; Chen, L.; Deng, Y.; He, X. A multilevel converter topology with fault-tolerant ability. IEEE Trans. Power Electron. 2005, 20, 405-415. [CrossRef]

147. Jin, F.; Liu, F.; Ruan, X.; Meng, X. Multi-Phase Multi-Level LLC Resonant Converter with Low Voltage Stress on the Primary-Side Switches. In Proceedings of the IEEE Energy Conversion Congress and Exposition (ECCE), Pittsburgh, PA, USA, 14-18 September 2014; pp. 4704-4710.

148. Kirshenboim, O.; Peretz, M.M. Combined Multilevel and Two-Phase Interleaved LLC Converter with Enhanced Power Processing Characteristics and Natural Current Sharing. IEEE Trans. Power Electron. 2018, 33, 5613-5620. [CrossRef]

149. Peter, A.K.; Mathew, J. A Single Phase, Single Stage AC-DC Multilevel LLC Resonant Converter With Power Factor Correction. IEEE Access 2021, 9, 70884-70895. [CrossRef]

150. Alatai, S.; Salem, M.; Ishak, D.; Kamarol, M.; Jamil, M.; Bughneda, A. Design and Analysis of Five-level Cascaded LLC Resonant Converter. In Proceedings of the 2020 IEEE International Conference on Power and Energy (PECon), Penang, Malaysia, 7-8 December 2020; pp. 66-70.

151. Poorfakhraei, A.; Narimani, M.; Emadi, A. A Review of Multilevel Inverter Topologies in Electric Vehicles: Current Status and Future Trends. IEEE Open J. Power Electron. 2021, 2, 155-170. [CrossRef]

152. Kawa, A.; Stala, R. SiC-Based Bidirectional Multilevel High-Voltage Gain Switched-Capacitor Resonant Converter with Improved Efficiency. Energies 2020, 13, 2445. [CrossRef]

153. Cui, W.; Shao, S.; Zhang, J.; Li, Y.; Zhang, J. Bidirectional Modular Multilevel Resonant DC-DC Converter for Medium Voltage Power Conversion. In Proceedings of the 2020 IEEE Energy Conversion Congress and Exposition (ECCE), Detroit, MI, USA, 11-15 October 2020; pp. 4380-4385.

154. Choi, W.-Y.; Yang, M.-K. Soft-Switching Bidirectional Three-Level DC-DC Converter with Simple Auxiliary Circuit. Electronics 2019, 8, 983. [CrossRef]

155. Jiao, Y.; Jovanović, M.M. Topology Evaluation and Comparison for Isolated Multilevel DC/DC Converter for Power Cell in Solid State Transformer. In Proceedings of the 2019 IEEE Applied Power Electronics Conference and Exposition (APEC), Anaheim, CA, USA, 17-21 March 2019; pp. 802-809.

156. Inoue, S.; Akagi, H. A Bi-Directional DC/DC Converter for an Energy Storage System. In Proceedings of the APEC 07-TwentySecond Annual IEEE Applied Power Electronics Conference and Exposition, Anaheim, CA, USA, 25 February-1 March 2007; pp. 761-767.

157. Kondrath, N. Bidirectional DC-DC Converter Topologies and Control Strategies for Interfacing Energy Storage Systems in Microgrids: An Overview. In Proceedings of the 2017 IEEE International Conference on Smart Energy Grid Engineering (SEGE), Oshawa, ON, Canada, 14-17 August 2017; pp. 341-345.

158. Chandrasekar, B.; Nallaperumal, C.; Padmanaban, S.; Bhaskar, M.S.; Holm-Nielsen, J.B.; Leonowicz, Z.; Masebinu, S.O. Nonisolated high-gain triple port DC-DC buck-boost converter with positive output voltage for photovoltaic applications. IEEE Access 2020, 8, 113649-113666. [CrossRef]

159. Abosnina, A.A.; Moschopoulos, G. A Novel Three-Phase Bidirectional DC-DC Converter for UPS Applications. In Proceedings of the 2018 IEEE Applied Power Electronics Conference and Exposition (APEC), San Antonio, TX, USA, 4-8 March 2018; pp. 1506-1513.

160. Sri, G.S.; Subbulekshmi, D. LLC Resonant Converter for Battery Charging Application. Int. J. Electr. Eng. 2015, 8, $379-388$.

161. Chen, W.; Wu, X.; Yao, L.; Jiang, W.; Hu, R. A Step-up Resonant Converter for Grid-Connected Renewable Energy Sources. IEEE Trans. Power Electron. 2015, 30, 3017-3029. [CrossRef]

162. Vakacharla, V.R.; Rathore, A.K. Isolated soft switching current fed lcc-t resonant DC-DC converter for pv/fuel cell applications. IEEE Trans. Ind. Electron. 2019, 66, 6947-6958. [CrossRef]

163. Islam, M.R.; Guo, Y.; Zhu, J. A high-frequency link multilevel cascaded medium-voltage converter for direct grid integration of renewable energy systems. IEEE Trans. Power Electron. 2014, 29, 4167-4182. [CrossRef]

164. Kumar, J.; Xavier, A.; Sujith, S. A Fuel Cell based Seven Level Hybrid Cascaded H-bridge Multilevel Inverter. Int. J. Eng. Res. Technol. (IJERT) 2020, 09, 20-25.

165. Dhanamjayulu, C.; Khasim, S.R.; Padmanaban, S.; Arunkumar, G.; Holm-Nielsen, J.B.; Blaabjerg, F. Design and implementation of multilevel inverters for fuel cell energy conversion system. IEEE Access 2020, 8, 183690-183707. [CrossRef]

166. Khan, F.; Tang, Y.; Sicheng, G. A Bidirectional Resonant DC-DC Converter for Electrical Vehicle Charging/Discharging Systems. Int. J. Comput. Appl. 2017, 177, 20-24. [CrossRef]

167. Qu, L.; Wang, X.; Bai, Z.; Liu, Y. Variable CLLC Topology Structure Technique for a Bidirectional on Board Charger of Electric Vehicle. In Proceedings of the 2019 4th International Conference on Power and Renewable Energy (ICPRE), Chengdu, China, 21-23 September 2019; pp. 185-189. 
168. Leite, R.S.; Afonso, J.L.; Monteiro, V. A novel multilevel bidirectional topology for on-board ev battery chargers in smart grids. Energies 2018, 11, 3453. [CrossRef]

169. Pernía, A.M.; Prieto, M.J.; Villegas, P.J.; Díaz, J.; Martín-Ramos, J.A. LCC Resonant Multilevel Converter for X-ray Applications. Energies 2017, 10, 1573. [CrossRef]

170. Jaisudha, S.; Srinivasan, S.; Gunasekaran, K. Bidirectional Resonant DC-DC converter for Microgrid Applications. Int. J. Power Electron. Drive Syst. 2017, 8, 1548.

171. Xuan, Y.; Yang, X.; Chen, W.; Liu, T.; Hao, X. A Novel Three-Level CLLC Resonant DC-DC Converter for Bidirectional EV Charger in DC Microgrids. IEEE Trans. Ind. Electron. 2021, 68, 2334-2344. [CrossRef]

172. Zhao, B.; Song, Q.; Liu, W.; Sun, Y. Overview of dual-active-bridge isolated bidirectional DC-DC converter for high-frequency-link power-conversion system. IEEE Trans. Power Electron. 2014, 29, 4091-4106. [CrossRef]

173. Alhamroun, I.; Salem, M.; Jusoh, A.; Idris, N.R.; Ismail, B.; Albatsh, F.M. Comparison of two and four switches inverter feeding series resonant converter. In Proceedings of the 2017 IEEE Conference on Energy Conversion (CENCON), Kuala Lumpur, Malaysia, 30-31 October 2017; pp. 334-338.

174. Barbi, I.; Pöttker, F. Soft Commutation Isolated DC-DC Converters; Springer: Berlin/Heidelberg, Germany, 2019.

175. Li-Jun, J.; Guang-Yao, Y.; Miao-Miao, J.; Yi-Fan, C.; Hai-Peng, Z.; Ke, Z. Study of Bi-Directional DC-DC Converter of Micro-Grid Hybrid Energy Storage System. In Proceedings of the IEEE 10th Conference on Industrial Electronics and Applications (ICIEA), Auckland, New Zealand, 15-17 June 2015; pp. 1166-1169.

176. Navas, M.A.H.; Lozada, F.; Puma, J.L.A.; Sguarezi Filho, A.J. Battery Energy Storage System Applied to Wind Power System Based On Z-Source Inverter Connected to Grid. IEEE Lat. Am. Trans. 2016, 14, 4035-4042. [CrossRef]

177. Aroliya, A.; Gautam, S.; Kumar, A.; Shrivastava, V. Analysis of Energy Storage System for Wind Power Generation with Application of Bidirectional Converter. In Proceedings of the Second International Conference on Computational Intelligence \& Communication Technology (CICT), Ghaziabad, India, 12-13 February 2016; pp. 419-423.

178. Jiang, T.; Zhang, J.; Wu, X.; Sheng, K.; Wang, Y. A bidirectional three-level LLC resonant converter with PWAM control. IEEE Trans. Power Electron. 2016, 31, 2213-2225. [CrossRef]

179. Bana, P.R.; Panda, K.P.; Padmanaban, S.; Mihet-Popa, L.; Panda, G.; Wu, J. Closed-loop control and performance evaluation of reduced part count multilevel inverter interfacing grid-connected PV system. IEEE Access 2020, 8, 75691-75701. [CrossRef]

180. Bana, P.R.; Panda, K.P.; Naayagi, R.; Siano, P.; Panda, G. Recently developed reduced switch multilevel inverter for renewable energy integration and drives application: Topologies, comprehensive analysis and comparative evaluation. IEEE Access 2019, 7, 54888-54909. [CrossRef]

181. Salem, M.; Ramachandaramurthy, V.K.; Jusoh, A.; Padmanaban, S.; Kamarol, M.; Teh, J.; Ishak, D. Three-Phase Series Resonant DC-DC Boost Converter With Double LLC Resonant Tanks and Variable Frequency Control. IEEE Access 2020, 8, 22386-22399. [CrossRef]

182. Trabelsi, M.; Vahedi, H.; Abu-Rub, H. Review on Single-DC-Source Multilevel Inverters: Topologies, Challenges, Industrial Applications, and Recommendations. IEEE Open J. Ind. Electron. Soc. 2021, 2, 112-127. [CrossRef]

183. Mukherjee, N.; Strickland, D. Analysis and comparative study of different converter modes in modular second-life hybrid battery energy storage systems. IEEE J. Emerg. Sel. Top. Power Electron. 2016, 4, 547-563. [CrossRef]

184. Eroğlu, F.; Kurtoğlu, M.; Vural, A.M. Bidirectional DC-DC converter based multilevel battery storage systems for electric vehicle and large-scale grid applications: A critical review considering different topologies, state-of-charge balancing and future trends. IET Renew. Power Gener. 2021, 15, 915-938. [CrossRef]

185. Abu-Rub, H.; Holtz, J.; Rodriguez, J.; Baoming, G. Medium-voltage multilevel converters-State of the art, challenges, and requirements in industrial applications. IEEE Trans. Ind. Electron. 2010, 57, 2581-2596. [CrossRef] 